\title{
Muscle Strength to Mental Strength: Exercise and Age-Related Cognitive Decline
}

\author{
Rhianna A. Lovegrove, Mark Bahr \\ School of Psychology, Bond University, Gold Coast, Australia \\ Email: rlovegro@bond.edu.au
}

How to cite this paper: Lovegrove, R. A., \& Bahr, M. (2020). Muscle Strength to Mental Strength: Exercise and Age-Related Cognitive Decline. Psychology, 11, 763-795. https://doi.org/10.4236/psych.2020.115052

Received: April 24, 2020

Accepted: May 26, 2020

Published: May 29, 2020

Copyright $\odot 2020$ by author(s) and Scientific Research Publishing Inc. This work is licensed under the Creative Commons Attribution International License (CC BY 4.0).

http://creativecommons.org/licenses/by/4.0/ (c) (i) Open Access

\begin{abstract}
As the population replacement rate exceeds the birth rate, the median age of the population in Western countries increases. With increasing age there is a rise in population disease burden, particularly in mental health. As such, there is considerable interest in the identification of modifiable factors that may protect against cognitive aging. In this study, 71 participants, across three age-balanced groups (young, 18 - 21; middle-aged, 22 - 47 years; older adults, 48+) were recruited from the general Australian community to examine the effect of aerobic versus resistance exercise on executive functioning (EF). As hypothesized, older adults evidenced decline in self-reported executive functioning (EF) impairment, and some aspects of mental flexibility. Multivariate Analysis of Variance (MANOVA) revealed that moderate to high aerobic exercise engagement, and moderate resistance exercise engagement may be somewhat beneficial for reducing age-associated performance decrements in mental flexibility. A dissociation of mental flexibility from spatio-temporal tracking performance provides support for a modular decline model of cognitive aging.
\end{abstract}

\section{Keywords}

Cognitive, Aging, Executive Functioning, Aerobic Exercise, Resistance Exercise

\section{Introduction}

There is a general belief that age-related cognitive decline is first detectable somewhere between the fifth and sixth decade of life (Karlamangla, Lachman, Han, Huang, \& Greendale, 2017; Rönnlund, Nyberg, Bäckman, \& Nilsson, 2005). Salthouse's $(2009,2011)$ longitudinal research, however, identified that some aspects of cognition begin to decline relatively early in adulthood. This decline 
appears to be most prominent for executive functioning (EF), higher-order frontal-lobe cognitive processes akin to the "CEO of the brain" (Chang \& Etnier, 2009; Yuan \& Raz, 2014). Such functions are involved with monitoring and regulating goal-directed behaviour, including planning and organizing, attentional processing, prospective memory, task switching, time and motion perception, inhibition, problem solving and decision-making (Harada, Natelson Love, \& Triebel, 2013). There is considerable evidence indicating that EF decline in neurotypical elderly is pronounced in the prodromal stages of dementia; a pathological form of decline encompassing a range of neurodegenerative conditions (Blacker et al., 2007; Clark et al., 2012; Deary et al., 2009; Petersen et al., 2001). Globally, a new case of dementia is detected every four seconds (World Health Organization and Alzheimer's Disease International; WHO, 2012), and as of 2017, dementia was deemed the second leading cause of death in Australia (Australian Bureau of Statistics, ABS, 2017; see Table 1). For these reasons, understanding the nature of cognitive aging and identifying factors that may protect against its onset are of public health significance.

Despite the inevitability of typical cognitive aging, its etiology is not fully understood. The most frequently endorsed theoretical viewpoint posits that, with age, individuals experience a generalized global slowing of all cognitive abilities attributed to a range of organic influences (Birren, 1964; Salthouse, 1996). These include beta-amyloid plaque build-up, vascular damage, and oxidative stressors; all of which insult the nervous system and consequently impair cognitive functioning in a synchronous manner (Birren, 1964; Cosentino et al., 2010; Donohue et al., 2017; Knopman et al., 2018; Salthouse, 1996). Research in support of this model has reported subtle but uniform age-associated declines across various cognitive domains such as reaction time, working memory, verbal recall, visual-spatial attention, reasoning, mental flexibility and response inhibition (Harada et al., 2013; Mahncke, Bronstone, \& Merzenich, 2006). A contrasting modular decline theory maintains that specific cognitive functions are more susceptible to senescence and thus, decline occurs within distinctive sub-systems (Geerligs, Renken, Saliasi, Maurits, \& Lorist, 2014). For example, profound EF deficits are not uncommon with increasing age (Healey, Campbell, \& Hasher, 2008; Salthouse, 2009; Schroeder \& Salthouse, 2004; Karlamangla et al., 2017;

Table 1. Leading causes of death in australia: From 2012 to 2017.

\begin{tabular}{cccc}
\hline Cause & \multicolumn{3}{c}{ Time } \\
\cline { 2 - 4 } & 2012 & 2017 & Change (\%) \\
\hline Ischaemic heart diseases & 20,108 & 18,590 & -7.50 \\
Dementia, including Alzheimer Disease & 10,367 & 13,729 & +32.43 \\
Cerebrovascular diseases & 10,785 & 10,186 & -5.55 \\
Chronic lower respiratory diseases & 6647 & 8357 & +25.73 \\
\hline
\end{tabular}

Note. $\%=$ percentage change in disease prevalence from 2012-2017. 
Uttl, 2008). Other crystallized cognitive domains (i.e. vocabulary, general knowledge, emotion recognition), however, tend to remain in-tact or steadily improve (Aartsen, Smits, van Tilburg, Knipscheer, \& Deeg, 2002; Alexander, Bahr, \& Hicks, 2014; Glisky, Polster, \& Routhieaux, 1995; Godefroy, Roussel, Despretz, Quaglino, \& Boucart, 2010; Kramer \& Willis, 2002). Evidently whether cognitive aging is modular or generalized remains elusive.

In addition to the ambiguity surrounding the nature of cognitive aging, it should also be noted that only half of the variability in cognitive decline can be explained by age-related neuropathology (Boyle et al., 2013). Instead, it appears that modifiable lifestyle factors have some protective value for buffering against cognitive aging (Stern, 2009, Stern et al., 2018; Vemuri et al., 2012; Yaffe et al., 2009). Recent evidence from $48.4 \%$ of the dementia cases in Australia revealed that $17.9 \%$ of the population's risk of developing dementia is the result of low physical activity engagement (Ashby-Mitchell, Burns, Shaw, \& Anstey, 2017). Indeed, a large body of geriatric literature supports that exercise can reduce the likelihood of brain exposure to Alzheimer's Disease (AD) neurotoxins (e.g., amyloid-tau proteins; Brown et al., 2013), decrease vascular pathology (atherosclerosis and hypertension), enhance oxygen transport efficiency to the brain (Lin et al., 2015), and increase brain growth factors such as Brain Derived Neurotrophic Factor (BDNF; Goldfield et al., 2018; Komulainen et al., 2008; Vaughan et al., 2014). Notably, a recent systematic review and meta-analysis of 48 studies concluded that exercise training significantly improves the cognitive functionality of individuals aged 60 or older (Falck, Davis, Crockett, \& Liu-Ambrose, 2019).

Literature assessing the impact of disparate exercises on the cognitive reserve of older adults is of greater significance for informing the development of intervention targeting cognitive decline. The most recent large-scale meta-analyses suggested that regular engagement in aerobic exercise can significantly improve the EF of older adults (Smith et al., 2010; Vaportzis, Niechcial, \& Gow, 2019). The reigning hypothesis is that aerobic exercise may counter age-related decline via an increase in cardiorespiratory fitness, commonly operationalised as an increase in an individual's maximum oxygen consumption rate $\left(\mathrm{VO}_{2} \max \right)$ and cerebral blood flow (Barnes et al., 2003; Horder et al., 2018; Labelle et al., 2014; Pensel et al. 2018; Prakash et al., 2011; Predovan, Julien, Esmail, \& Bherer, 2019). Aerobic-exercise induced increases in cerebral blood blow are linked to a reduction in the accumulation of neuropathological markers (e.g., Amyloid- $\beta$ ) implicated in cognitive decline pathology (Voss, Nagamatsu, Liu-Ambrose, \& Kramer, 2011). Fitness increases are associated with heightened brain activity during executive control tasks (Wong et el., 2015), lessened cerebral vasculature damage caused by arteriosclerosis (Mitchell et al., 2011; Pase et al., 2016; Tabara et al., 2007), and a reduction in systemic immune activation (Muscari et al., 2010).

Despite this, some evidence has challenged the notion that increases in aerobic exercise amounts translates to linear improvements in cognitive functioning. Etnier, Nowell, Landers, and Sibley's (2006) meta-analytic results found no sig- 
nificant linear or curvilinear relationship between fitness and cognitive functionality. Similarly, Young, Angevaren, Rusted and Tabet's (2015) review of 12 randomized control trials (RCT), including 754 participants over the age of 55, concluded that aerobic exercise induced increases in cardiorespiratory fitness were not significantly accompanied by significant cognitive changes. Snowden et al. (2011) also reported no significant overall benefit of aerobic exercise across 30 studies that measured numerous cognitive domains (e.g., general cognition, reaction time, memory, attention, processing speed, visuospatial ability and language processing). Of note, however, is the extent to which studies included within the above reviews vary in methodological rigor. Young et al. noted that randomization methods were often unclear, attrition was underreported, contamination bias was present, and ceiling effects were suspected. Snowden et al. also reported underpowered studies and consistent use of instruments insensitive for detecting age-associated decline, such as the Mini-Mental State Examination (MMSE; Folstein, Folstein, \& McHugh, 1975). St. John, Montgomery, Kristjansson, and McDowell (2002) indicated that the MMSE is prone to ceiling effects -poor sensitivity for detecting subtle cognitive changes in neurotypical adults, with scores in the "normal" range predicting institutionalization and aged-related mortality. Additional evidence suggests that the measure is easily invalidated by practice effects, has poor test-retest reliability and lacks construct validity for detecting modular declines in cognition (Gaffney et al., 1995; Spencer et al., 2013).

The role of resistance exercise in enhancing cognitive reserve has received less attention. The mechanism by which resistance exercise may exert positive effects on cognition, however, is understood to be the result of enhanced insulin-like growth factor-1 (IGF-1) promoting the growth, survival and differentiation of neurons implicated in protecting against age-associated pathology (Cotman \& Berchtold, 2002; Herold, Torpel, Schega, \& Muller, 2019; Liu-Ambrose \& Donaldson, 2009). Results from a recent meta-analysis by Landrigan, Bell, Crowe, Clay, and Mirman (2019) reported that across 24 studies, resistance training had an overall positive effect on cognitive impairment. Similarly, Wilke et al. (2019) concluded that a singular session of acute resistance exercise training has a positive effect on global cognition, and cognitive flexibility. More specifically, A 12-month resistance exercise intervention by Liu-Ambrose, Nagamatsu, Voss, Khan, and Handy (2012) reported that moderate, but not low levels of resistance training (twice-weekly) in 155 women, aged 65 to 75, enhanced response inhibition and selective attention. On a related note, Cassilhas et al. (2007) reported no significant difference in EF when comparing the impact of moderate and high frequency resistance exercise training over a six-month RCT. These findings raise the question as to whether there is a threshold whereby resistance exercise engagement no longer induces cognitive performance benefits.

Alternative findings suggest that larger quantities of resistance training may be associated with significant improvements in selective attention, but not mental flexibility or processing speed (Chang \& Etnier, 2009). It is possible that only 
some EF's are influenced by resistance training, providing indirect support for modular decline. Alternatively, the measures used may not be sensitive enough to detect the effects of resistance exercise on cognition. Other studies, however, such as Ruiz et al. (2015), found no statistically significant changes in cognitive status on the MMSE following a two-month resistance exercise intervention. Similarly, Alves et al. (2012) reported that participants who engaged in an acute resistance exercise intervention experienced no significant change in mental flexibility (task switching), as measured by the TMT. Kimura, Yasunaga, and Wang (2013) also concluded that three months of resistance training did not improve cognition as measured by the MMSE, nor did it significantly influence mental flexibility on the TMT. Short term, acute exercise interventions consistently appear to have little cognitive benefit for older adults.

It seems that increasing aerobic exercise engagement is beneficial for mitigating the effects of cognitive decline by enhancing cardiorespiratory fitness. Emerging research also suggests long-term resistance training may be beneficial for enhancing cognitive performance on EF tasks. Considering that not all adults can avail themselves with aerobic exercise due to physical limitations (Latorre-Roman, Laredo-Aguilera, Garcia-Pinillos, Soto-Hermoso, \& Carmona-Torres, 2018), additional evidence for resistance training eliciting a cognitive benefit would provide an alternate means for preserving brain health in the elderly. There is considerable variability, however, in how researchers define resistance and aerobic exercise. Recent large-scale meta-analyses have amalgamated varying regimes (i.e., resistance, balance, strength, cardiovascular) into one category, rendering comparative conclusions invalid (Sanders, Hortobagyi, Bastide-van Gemert, van der Zee, \& van Heuvelen, 2019). There is also ambiguity regarding the optimal dosage of exercise (quantity, frequency, intensity, and duration) beneficial for enhancing cognitive resilience.

To the author's knowledge, only one RCT by Coetsee and Terblanche's (2017) has directly compared the relative EF benefits of resistance training versus aerobic exercise among older adults. This study involved a 16-week exercise intervention whereby 67 sedentary individuals aged 55 to 75 years old were assigned to either a moderate continuous aerobic training, high intensity aerobic interval training, resistance training, or control group. Results revealed that participants in the high intensity aerobic-interval training group displayed the most prominent improvements in processing speed, whereas participants in the moderate continuous aerobic exercise group experienced the most improvement on executive control tasks. With limited available evidence, however, the question remains as to which type and amount of exercise is most beneficial for EF performance across the lifespan.

\section{Aims and Hypotheses}

Thus, the current study aimed to conduct a cross-sectional, quasi-experimental conceptual replication of Coetsee and Terblanche's (2017) work, by investigating the relative impacts of self-reported aerobic versus resistance exercise engagement on the EF of adults aged 18 to 76 years old. To further investigate the 
theoretical debate as to whether age-related cognitive decline is modular or generalized, the current study also assessed for performance dissociation across three distinct measures of EF, including: The Trail Making Task (measuring mental flexibility), the Time Wall Task (measuring spatial-temporal tracking), and the Bond Revised Executive Functioning Test (BREFT); a newly developed paper-based self-report measure of EF. In accordance with research suggesting that mental flexibility declines with age (Karlamangla et al., 2017; Salthouse, 2009; Schroeder \& Salthouse, 2004), it was expected performance on the TMT mental flexibility outcomes (i.e. reaction time, problem solving inefficiency, total time completion, and perseverative error), and EF scores on the BREFT would decline with increasing age. With evidence indicating that aerobic exercise engagement is associated with superior EF (Young et al., 2015), it was hypothesized that at low levels of aerobic exercise engagement, older individuals would display poorer mental flexibility on the TMT and greater impairment on the BREFT, compared to middle-aged and younger participants, respectively. Based on Liu-Ambrose et al. (2012) findings it was expected that at low levels of resistance exercise engagement, older adults would exhibit poorer mental flexibility on the TMT and greater impairment on the BREFT, compared to middle-aged and younger participants. Finally, in line with the modular cognitive decline theory and recent literature (Mueller \& Piper; 2014; Piper et al., 2012), it was hypothesized that older adults would display significantly poorer performance on the TMT task, relative to their performance on the TWT. Evidence for differential task performance would provide support for a modular account of age-related decline. No significant differentiation in performance between tasks would be indicative of generalized decline.

\section{Method}

\subsection{Participants}

The sample size for the current study was estimated a priori, using $G$ * Power Version 3.1.9.3 (Faul, Erdfelder, Lang, \& Buchner, 2007). With the alpha level of significance set at 0.05 , and power at 0.80 , it was determined that 63 participants were required to detect a small effect $\left(f^{2}=0.15\right)$. Given that attrition is common in experimental research, the sample size estimate was increased by $10 \%$; to 70 participants (Nayak, 2010). The final sample comprised 71 volunteer participants (45 females, 26 males), aged 18 to 76 years old $(M=37.16, S D=19.33)$. Subjects from Queensland and Tasmania were recruited via social networking groups, university colleague connections, and the Bond University research participant pool for undergraduate psychology students. Purposive sampling was deemed the most suitable method to ensure equal representation of participants across three age brackets: young $(\leq 21)$, middle-aged $(21-47)$ and older $(48+)$. A chi-square analysis confirmed that cell sizes were equal across age groups, $\eta^{2}(2$, $\mathrm{n}=71)=0.37, p=0.833$.

An inclusion criterion stipulated that participants be at least 18 years old, with 
normal to corrected vision (previous studies have noted that visual impairments are problematic for older adults when navigating computer-administered neuropsychological tasks; Helmes \& Harris, 2017; Roudaia, Bennet, Sekuler, \& Pilz, 2010). A post-hoc exclusion criterion also ensured that participants with known cognitive deficit(s), independent of the typical aging trajectory, were excluded. Notably, 37 (52.1\%) participants were single and 34 (47.9\%) were in a relationship. There were $25(36.8 \%)$ participants who had completed education up to Year 12, 24 (35.3\%) had an undergraduate degree, and only 7 (10.3\%) had completed post-graduate education. There were $52(76.5 \%)$ participants born in Australia. To check for differences in aerobic and resistance exercise engagement by age, two $3 \times 3$ cross-tabulation chi-square analyses were conducted. There was no significant difference in aerobic exercise engagement, by age, $\eta^{2}(4, \mathrm{n}=$ $71)=7.58, p=0.108$. There was, however, a significant difference between expected and observed cell sizes for resistance exercise, across age groups, $\eta^{2}(4, \mathrm{n}$ $=71)=24.41, p<0.001$. Older participants were over-represented in the low resistance exercise category, whereas younger participants were over-represented in the high resistance exercise category.

\subsection{Materials}

Demographic Questionnaire. The 13-item demographic questionnaire was developed to obtain basic participant information including age in years, gender, highest level of education, country of birth, relationship status, number of fluent languages, medical health and vision status. Responses were provided via a Google Forms questionnaire (can be provided upon request).

Bond Revised Executive Functioning Test (BREFT; Lovegrove, Bahr, \& Vashist, 2020). Adapted from Bailey's (2018) 16-item EF deficit test from the ADDitude: Inside the ADHD mind online magazine, the BREFT is a 28 -item behavioural checklist that measures EF in neurotypical adults. Given that EF's are typically measured via cumbersome computer-administered tasks, the BREFT was designed as a paper-based, self-report alternative that measures three domains of EF: prospective memory, distractibility, and planning. In accordance with Payne's (1980) guidelines for test development, double-barreled questions from the original magazine were separated, and some items were reflected to include both positively ( 16 items) and negatively (13 items) worded composites. The order of question presentation was randomized to negate the influence of response bias, and 12 additional items were added to enhance construct validity. An example item for distractibility is: "I can remain focused on tasks." An example item for planning is: "I plan which tasks are more important”. Responses are provided on a 5-point scale, ranging from Not Often (1), to Often (5), or from Strongly Disagree (1) to Strongly Agree (5). A total EF score was calculated by subtracting the sum of the negatively worded items (impaired $\mathrm{EF}$ ), from the sum of positively worded items (normal EF). Higher positive scores are indicative of better EF performance, whereas higher negative scores indicate greater impairment. 
A reliability analysis of the BREFT was recently conducted using a subset of questions (15 items). Results indicated that the measure has excellent internal consistency ( $\alpha=0.91$; Cronbach, 1951). Data from the current study was combined with additional data from a separate project to form a sample size appropriate for conducting a factor analysis $(\mathrm{N}=146$; Tabachnik \& Fidell, 2013). The Kaiser-Meyer-Olkin's $(\mathrm{KMO})$ statistic $(\mathrm{r}=0.91)$ was within the acceptable range of 0.50 to 0.80 , revealing the data was suitable for exploratory factor analysis (EFA; Kaiser, 1974). Principal Axis Factoring, with an oblimin rotation was used to identify the latent factors underpinning the BREFT. The solution of best fit was a one-factor model, accounting for $44.87 \%$ of the variance. It was therefore concluded that this subset of the BREFT measured a unidimensional EF construct. Further psychometric validation is required.

Recent Physical Activity Questionnaire-Revised (RPAQ-R; Lovegrove \& Bahr, 2020). The RPAQ- $R$ is a shortened and modified version of Golubic et al.'s (2014) 57-item RPAQ; a measure of physical activity engagement over the past month, across four domains (leisure time, occupation, commuting, and domestic life). As noted by Younan (2018), loose definitions of what constitutes physical exercise in conjunction with inconsistent operationalization of aerobic and resistance exercise programs, makes it fundamentally impossible to draw valid conclusions from existing research. The RPAQ-R was modified to address these methodological concerns. The questionnaire includes two subsections adapted from the original RPAQ section C, pertaining to recreational exercise behaviour. Subsections contained 35 items corresponding to 35 different physical activities (e.g., jogging), for the purpose of measuring aerobic and resistance exercise engagement. Criterion validity of the RPAQ-R was established by referring to exercise categorisation within existing physical activity measures (e.g., CHAMPS Physical Activity Questionnaire; Stewart et al., 2001). Proceeding a post-hoc revision of the scale, the final RPAQ-R measure comprised 19 items. A copy of the items corresponding to their respective categories can be provided upon request.

Participants respond by rating their engagement with each activity in the past four weeks, on a scale ranging from None (0), Once (1), 2 - 3 Times (2), Weekly (3), 2 - 3 Times Per Week (4), 4 - 5 Times Per Week (5), to Daily (6). A total aerobic exercise engagement score was calculated by summing scores from all aerobic items. Likewise, a total resistance exercise engagement score was determined by the sum of all resistance exercise items. Participants were further categorized as having low, moderate, or high aerobic and resistance exercise engagement. Engagement levels were defined by a natural break using histogram distributions. Low resistance exercise was defined as 0 - 1 exercise(s), moderate was 2 - 8 exercises, and high was 9 or more exercises. Low aerobic was $1-6$ exercises, moderate was $7-8$ and high was 9 or more exercises. Although the RPAQ-R's psychometric properties have not yet been established, the original RPAQ has been validated on a population of 2000 adults across ten European countries (Golubic et al., 2014). The measure has good test-retest reliability over a two-week period, with an intra-class correlation coefficient of $0.76(p<0.001)$ 
for measuring total physical activity expenditure. Moderate correlations $(\mathrm{r}=0.3)$ between RPAQ activity levels and objective criterion measures of activity (i.e., HR monitor, movement sensors) were also found.

Trail Making Test (TMT; Piper et al., 2012). The TMT is a standardized, computer-administered neuropsychological measure of mental flexibility provided by the PEBL software. Originally forming part of the Halstead-Reitan Test Battery (Reitan \& Wolfson, 1985), the original TMT is among the most employed neuropsychological tests in clinical practice and experimental research (Strauss, Sherman, \& Spreen, 2006). The TMT takes approximately 10 minutes to complete and requires participants to, as accurately as possible, move a computer mouse in a predetermined sequence to connect sets of 25 dots on a $7 \times 7$ grid, within a 20 second time frame across eight trials. The test comprises two parts: Part A (TMT-A), a test of visual attention where participants connect ascending numbers 1 to 13 (Trails Part A: 1-2-3-4-5) and Part B (TMT-B), a test of mental flexibility, where participants connect alternating numbers 1 to 13 , or letters A to L (Trails Part B: 1-A-2-B-3). It has been established that error rate and total time to completion on the TMT are independently meaningful scores. Thus, both have valid clinical utility for assessing cognitive decline (Ashendorf et al., 2008; Harvey \& Bowie, 2006; Tombaugh, 2004). Moreover, given that the TMT-A provides a baseline measure of visual attention and the TMT-B is thought to add an additional demand of set switching, Oosterman et al. (2010) concluded that a ratio score of TMT-B to TMT-A should also be considered. Thus, the current study incorporated the following four composite EF outcomes. 1) A total time completion ratio of TMT-B (singular characters) to TMT-A (set switching between characters), whereby ratios greater than 1.0 indicate poorer mental flexibility. 2) A reaction time ratio of TMT-B: TMT-A, where higher values are indicative of slower reaction time and therefore less mental flexibility. 3) Perseverative error score, operationalized as a ratio of over-clicks on the TMT-B compared to the TMT-A. Perseveration refers to the tendency to persist with the same response despite feedback indicating the responses are incorrect (Demakis, 2003). It has been found that perseverative increases with age and is dependent upon prefrontal cortex EF processing (Head, Kennedy, Rodrigue, \& Raz, 2009). Higher perseveration ratios are indicative of less mental flexibility. Finally, as proposed by Correia et al. (2015), problem-solving efficiency was also measured. 4) This was calculated by summing the number of clicks that participants needed to complete the task, expressed as a ratio of TMT-B: TMT-A. A higher ratio indicates more inefficient problem solving.

Regarding the TMT's psychometric properties, Mueller and Piper (2014) reported acceptable test-retest reliability for TMT-A $(r=0.74)$ and TMT-B $(r=$ 0.61 ), with a 20-week interval. Convergent and construct validity have also been established, with Sanchez-Cubillo et al. (2009) reporting that scores on the TMT-A are significantly associated with visual search speed on the WAID-III Digital Symbol score. Similarly, scores on the TMT-B have been significantly predicted by Wisconsin Card Sorting Test Perseverative Errors, an alternative 
neuropsychological index of executive control and set switching (Chaytor, Schmitter-Edgecombe, \& Burr, 2006). There is also some evidence for discriminant validity, such that performance on interference control tasks (i.e., the Stroop Colour-Word Task) does not significantly predict TMT-B scores (Sanchez-Cubillo et al., 2009). A moderate-high correlation between TMT-A and TMT-B $(r=0.73)$ also supports the general assumption that both parts measure some common cognitive factors, but are not redundant (Sanchez-Cubillo et al., 2009). This conclusion is further supported by Jacobson, Blanchard, Connolly, Cannon, and Garavan (2011) who identified that TMT-B relative to TMT-A, produces blood oxygen elevations in the inferior middle frontal gyri. The TMT has been consistently employed as a sensitive indicator of brain damage in persons aged 15 to 89 (Davidson, Gao, Mason, Winocur, \& Anderson, 2008; Kopp et al., 2015; Muir et al., 2015), and it has been established that older age groups show the greatest decline in performance on the TMT (Rasmusson et al., 1998). Piper et al. $(2012,2015)$ reported U-shaped associations between age and performance on the TMT-B, with improvements occurring throughout childhood, yet a significant regression occurring in late adulthood.

Time Wall Task (TWT; Piper et al., 2012). The TWT is a measure of spatio-temporal tracking broadly defined as the ability to process and interpret information regarding the location of moving objects in time and space (Klencklen, Despres, \& Dufour, 2011). The TWT originally formed part of the Unified Tri-Services Cognitive Performance Assessment Battery utilized by the military of the United States for personnel testing (Perez, Masline, Ramsay, \& Urban, 1987). The PEBL version of the TWT is a non-verbal proxy that requires participants to assess the time at which a target spot, moving vertically across a computer screen at a constant rate, travels to a fixed distance. The test comprises 20 trials, whereby which targets fall at randomly generated speeds. Participants are provided with feedback after each trial indicating whether their accuracy was, "Too Short," "Great," or "Too Long." The primary EF outcome utilized was mean inaccuracy; a proportionality score defined as the absolute value of the time difference between the actual response time and the correct time, divided by the correct time. Higher inaccuracy scores are indicative of poorer spatio-temporal tracking, with a perfect accuracy score being 0. Mueller and Piper (2014) reported that in a sample of 1233 participants, aged five to 89 years old, TWT performance was unaffected by age. Despite a paucity of literature specifically examining the TWT, evidence suggests that spatial-temporal tracking abilities remain intact with age (Roudaia \& Faubert, 2017; Wearden, Wearden, \& Rabbitt, 1997).

\subsection{Procedure}

Ethical approval for data collection was obtained from the Bond University Human Research Ethics Committee in accordance with the National Health and Medical Research Council's (NHMRC, 2018) National Statement on Ethical Conduct in Human Research. During an experimental session, participants were 
seated in front of a laptop facing a blank wall (to minimize distraction). Participants were instructed to read the Google Forms explanatory statement which outlined the purpose and significance of the study, the required completion time (approximately 30 minutes), the anonymous nature of data collection and their right to withdraw from the study at any time. Informed consent was provided and a unique personal identifier (UPI) code was generated to ensure data anonymity. Following the provision of consent, participants were presented with a series of survey measures including the demographic questionnaire, BREFT and RPAQ-R. The TMT and TWT neuropsychological tests were then administered. Counterbalancing was employed to reduce the influence of practice effects associated with technology familiarity (Goldberg, Harvey, Wesnes, Synder, \& Schneider, 2015). Also, importance was placed upon the standardization of instructions to aid in eliminating error variance due to experimenter effects. The verbal instructions modified from Piper et al.'s (2012) study can be observed below.

Verbal Instructions for the Demographic Questionnaire, BREFT and RPAQ. "You are about to take part in an experiment where you will complete a series of questionnaires over a 15 to 20-minute period. On the first questionnaire you will be asked to provide some basic demographic information (i.e., gender, age). The second will follow directly from the first, and will present you with a series of statements about everyday situations pertaining to how good your planning is, and how distracted you get, on a scale of $1-5$, where 1 indicates you strongly disagree, or the event from the statement does not happen often, and 5 means that you strongly agree, or that the event from the statement happens often. An example statement is: "I forget my appointments often."

The second questionnaire on the survey document will ask you about the types and amounts of exercises that you do. You will be presented with a series of physical activities (i.e., jogging), to which you must indicate how much you have engaged in that activity in the past four weeks (i.e., daily), using a 1 - 6 scale. You will also be required to indicate how long you typically complete each activity for (i.e., 20 minutes), using a scale of 1 - 5. Read and follow the written instructions, they re-explain everything I have just told you. If there are any questions, or parts of the form that are not clear to you, please ask for assistance. If at any stage you decide you do not want to continue with the study, you have the right to withdraw."

Verbal Instructions for the TMT and TWT Tasks. "The next two five-minute activities will be completed on my laptop and will test how quickly you can switch between tasks (i.e., your mental flexibility) and how accurate you are at detecting the speed at which something is moving (i.e., your spatio-temporal ability). The mental flexibility task aims to determine how quickly you can switch between letters and numbers as you connect them in a sequence on a grid format. You will complete eight $7 \times 7$ grids, that require you to either connect numbers in a sequence from $1-25$ (1-2-3-4), 13 letters $(A-L)$ in a sequence $(A-B-C-D)$ or switch between the two (A-1-B-2-C-3), by clicking on the charac- 
ters with the mouse. When you click on the correct character, the number or letter will go bold (within a circle on the grid) and a line will be drawn from the previous circle to the new circle. If you click on the circle with the wrong character, no line will be drawn, and you will not be able to move on until you choose the correct circle. You will get two mini-grid practise trials before completing the formal trials. Each grid will disappear after 20 seconds, indicating your time has run out for that specific grid. Your aim is to get through as much of the grid as possible, within the fixed time interval. So, try to be as quick as you can. Timing will begin when you click on the first circle which is labelled ' 1 ' or ' $A$ ' on any given trial.

The spatio-temporal task aims to see how well you can estimate the speed of a moving target. For each trial, when you press the spacebar, a small dot will drop from the top of the screen at a constant rate. When the dot reaches the red section, about two-thirds of the way down the screen, you will no longer be able to see it, it will pass behind a red wall. Your task is to imagine, if you were able to see the dot moving at the same rate, when it would have hit hole at the bottom screen. Specifically, your task is to press the space bar at the exact moment you think the dot would hit the hole. You will complete 20 trials, and the target dot will move at varying speeds across each trial. When making your estimate, do not use any strategies that will improve your performance, such as tracking the dot with your finger, or counting in your head. Instead, just follow the target with your eyes and try to use your judgement to visualise it moving when you can no longer see it. After each estimate, you will receive feedback on your accuracy, which will detail whether your performance was 'Great' (close to the actual target), 'Too Long' (over-estimation), or 'Too Short' (under-estimation). Take your time and try to be as accurate as possible."

At the conclusion of the experiment, participants were thanked for their time and provided with an opportunity to debrief.

\subsection{Design}

The current study utilized a quasi-experimental, cross-sectional design to determine if age-related decline in EF was more pronounced in participants who retrospectively reported less engagement in aerobic or resistance exercise. The first analysis utilized a 3 (Age: young, middle-aged, older) $\times 3$ (Resistance Exercise Engagement: low, moderate, high) $\times 3$ (Aerobic Exercise Engagement: low, moderate, high) multivariate Analysis of Covariance (MANCOVA) to investigate the relationship between age and aerobic versus resistance exercise engagement on EF. Cognitive reserve factors identified in prior literature as masking or confounding age-related decline were controlled for as covariates. These included: more years of formal education (Foverskov et al., 2018; Roe, Xiong, Miller, \& Morris, 2007), country of birth (Doblhammer, van den Berg, \& Fritze, 2013), employment status (Celidoni, Dal Bianco, \& Weber, 2017), being widowed or single (Feng et al., 2014; Zhang, Li, Xu, \& Liu, 2019), bilingualism (Gold, 2015; Houtzager, Lowie, Sprenger, \& de Bot, 2017; Yeung, St. John, Me- 
nec, \& Tyas, 2014), and being female (McCarrey, Kitner-Triolo, Ferrucci, \& Resnick, 2016; Zaninotto, Batty, Allerhand, \& Deary, 2018). No significant covariate effects were found. Thus, to avoid reductions in statistical power, they were removed for the proceeding analyses. Main analyses comprised Multivariate Analyses of Variance (MANOVA) and Factorial Analyses of Variance (ANOVA) to determine the effects of Age (young, middle-aged, old), Aerobic Exercise Engagement (low, moderate, high), and Resistance Exercise Engagement (low, moderate, high), on three Executive Functioning tasks 1) the Trail Making Task: perseverative error, total time completion, problem solving efficiency, reaction time, 2) the Time Wall Task: spatio-temporal tracking inaccuracy, and 3) the BREFT: EF impairment).

\section{Results}

All data was directly exported into the IBM Statistical Package for the Social Sciences (SPSS) version 26, for analysis. The data met the assumptions for performing multivariate analyses (Tabachnick \& Fidell, 2013). Unless otherwise stated, Wilks" Lambda approximation to F was reported, and all tests utilized $\alpha$ of 0.05 . Levene's Test of Equality of Error Variance was utilized to examine homogeneity of variance. Where violated, a more conservative $\alpha$ of 0.01 was adopted. A correlation matrix of the key variables can be observed in Table 2.

The multivariate interaction between Age and Resistance Exercise Engagement for Mental Flexibility was found to be significant, $\mathrm{F}(16,132)=2.14, p=$ $0.010, \eta_{\text {partial }}^{2}=0.16$, power $=0.88$. Similarly, a significant multivariate interaction was identified for Age $\times$ Aerobic Exercise Engagement, $\mathrm{F}(16,132)=2.26, p=$ $0.006, \eta_{\text {partial }}^{2}=0.17$, power $=0.90$. No significant multivariate three-way Age $\times$ Aerobic Exercise Engagement $\times$ Resistance Exercise Engagement interaction was observed, $\mathrm{F}(12,114)=1.37, p=0.188$. Similarly, the two-way interaction between Aerobic Exercise Engagement and Resistance Exercise Engagement was non-significant, $\mathrm{F}(16,132)=1.43, p=0.139$. Moreover, there was no significant main effect of Age, Resistance Exercise Engagement, or Aerobic Exercise Engagement on the combined Mental Flexibility variables, $\mathrm{F}(8,86)=1.49, p=$

Table 2. Correlation matrix for the TMT, TWT and BREFT variables.

\begin{tabular}{lccccccc}
\hline \multicolumn{1}{c}{ DV } & 1 & 2 & 3 & 4 & 5 & 6 & $M(S D)$ \\
\hline 1. Time Completion Ratio & - & & & & & & $0.73^{\mathrm{a}}(0.14)$ \\
2. Reaction Time Ratio & 0.12 & - & & & & & $1.00(0.00)$ \\
3. Problem Solving Inefficiency & -0.11 & -0.04 & - & & & & $-3.98(6.91)$ \\
4. Perseveration & -0.07 & -0.03 & $0.36^{* *}$ & - & & & $7.22(8.41)$ \\
5. BREFT Impairment & -0.08 & 0.05 & $-0.30^{*}$ & -0.15 & - & & $44.52(4.79)$ \\
6. TWT Inaccuracy & 0.09 & -0.16 & -0.35 & -0.10 & 0.07 & - & $0.06(0.02)$ \\
\hline
\end{tabular}

$N B . N=71 . M=$ Mean. $S D=$ Standard Deviation. ${ }^{*} p<0.05 .{ }^{*} p<0.01 .{ }^{a}=$ values transformed from raw data due to PEBL buffer underflow. 
$0.171 ; \mathrm{F}(8,86)=0.75, p=0.646 ; \mathrm{F}(8,86)=1.47, p=0.181$. At the univariate level, only the between-subjects interactive effect of Age $\times$ Resistance Exercise Engagement for Perseverative Error was significant, $\mathrm{F}(4,46)=2.79, p=0.037, \eta_{\text {partial }}^{2}$ $=0.20$, power $=0.72$. The interaction accounted for $20 \%$ of the total variance in Perseverative Error and is depicted in Figure 1.

\subsection{Resistance Exercise Engagement, Age, and Mental Flexibility}

Given the significant interaction, the data was split by Resistance Exercise Engagement level to assess the simple main effect of Ageon Perseverative Error, at each level of Resistance Exercise Engagement. A one-way between-groups univariate ANOVA was conducted in conjunction with post hoc follow up tests using Tukey's HSD. Results from the ANOVA highlighted that for low Resistance Exercise Engagement levels, there was a significant effect of Age on Perseverative Error, $F(2,18)=4.00, p=0.037, \eta_{\text {partial }}^{2}=0.31$, power $=0.64$. Age accounted for $31 \%$ of the variance. Post-hoc comparisons indicated that older adults $(M=13.54, S D=8.47)$ exhibited significantly more Perseverative Error than younger adults $(M=-1.00, S D=0.00)$. There was no significant difference, however, between younger and middle-aged adults $(M=7.67, S D=4.76)$, or between middle-aged and older adults. For participants who engaged in moderate Resistance Exercise, no significant effect Age on Perseverative Error was detected, $F(2,19)=0.79, p=0.470$. Mental flexibility across younger, middle-aged, and older adults did not differ significantly. At high levels of Resistance Exercise Engagement, there was a significant effect of Age on Perseverative Error, with age account for $34 \%$ of the variance, $F(2,22)=5.53, p=0.011, \eta_{\text {partial }}^{2}$

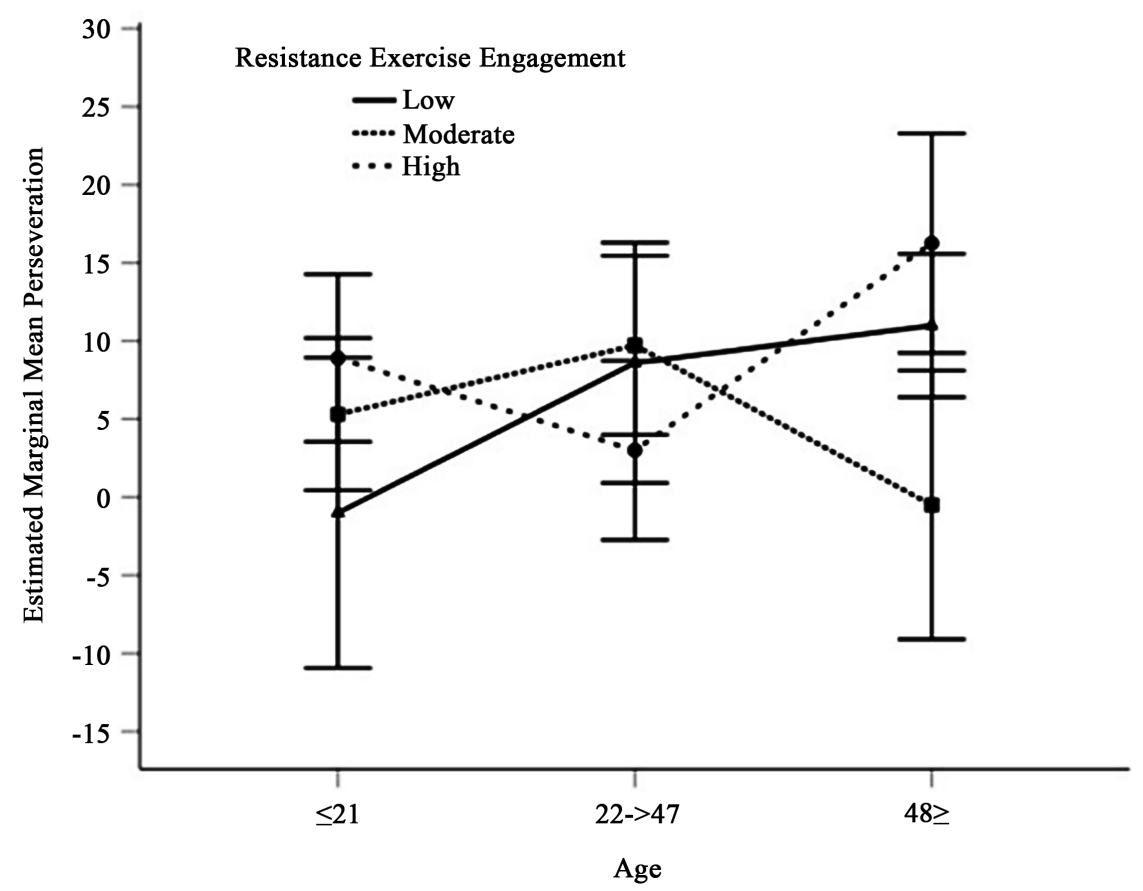

Figure 1. Mean perseveration score by age group, and level of resistance exercise. NB: Error bars $=95 \%$ Confidence Intervals (CI). 
$=0.34$, power $=0.80$. Younger adults $(M=6.00, S D=6.94)$ exhibited significantly less Perseverative Error than older adults $(M=16.25, S D=5.38)$. Similarly, older adults experienced significantly more Perseverative Error than middle-aged adults $(M=3.00, S D=5.29)$. No significant difference in Perseveration was observed between middle-aged and younger adults.

\subsection{Aerobic Exercise Engagement, Age, and Mental Flexibility}

To unpack the Age $\times$ Aerobic Exercise Engagement multivariate interaction, the file was also split by Aerobic Exercise Engagement and a series of MANOVA analyses were conducted. At low levels of Aerobic Exercise Engagement, the multivariate effect of Age on Mental Flexibility was significant, $F(8,46)=2.76, p$ $=0.014, \eta_{\text {partial }}^{2}=0.34$, power $=89$. Age accounted for $34 \%$ of the variance in mental flexibility at low levels of Aerobic Exercise. As can be seen in Figure 2, at the univariate level there was a significant effect of Age on Perseverative Error, $F(2,25)=5.56, p=0.010, \eta_{\text {partial }}^{2}=0.31$, power $=81$. Age accounted for $31 \%$ of the variance, with older adults $(M=15.89, S D=8.85)$ making significantly more Perseverative Errors than middle-aged adults $(M=4.00, S D=8.58)$. There was no significant difference in Perseverative Error between younger $(M=9.67, S D$ $=6.12$ ) and middle-aged, or younger, and older adults.

As seen in Figure 3, a significant effect of Age on Reaction Time Ratio was also observed at low levels of Aerobic Exercise, accounting for $37 \%$ of the variance, $F(2,25)=7.19, p=0.003, \eta_{\text {partial }}^{2}=0.37$, power $=90$. Younger adults $(M=$ $1.00, S D=0.00)$ had significantly slower Reaction Times than middle-aged adults $(M=1.00, S D=0.00)$. There was no significant difference, however, in

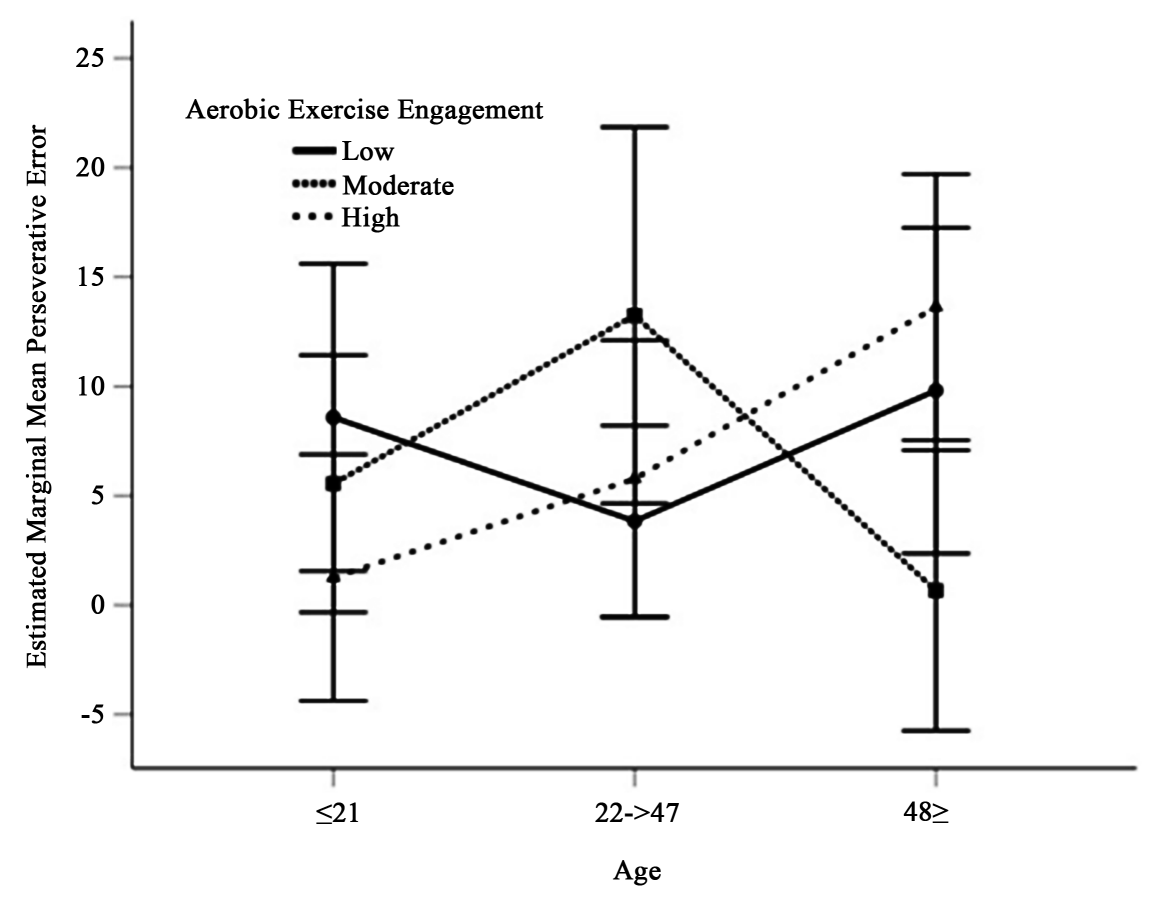

Figure 2. Mean perseveration score by age group, and aerobic exercise level. NB: Error bars $=95 \%$ Confidence Intervals $(\mathrm{CI})$. 


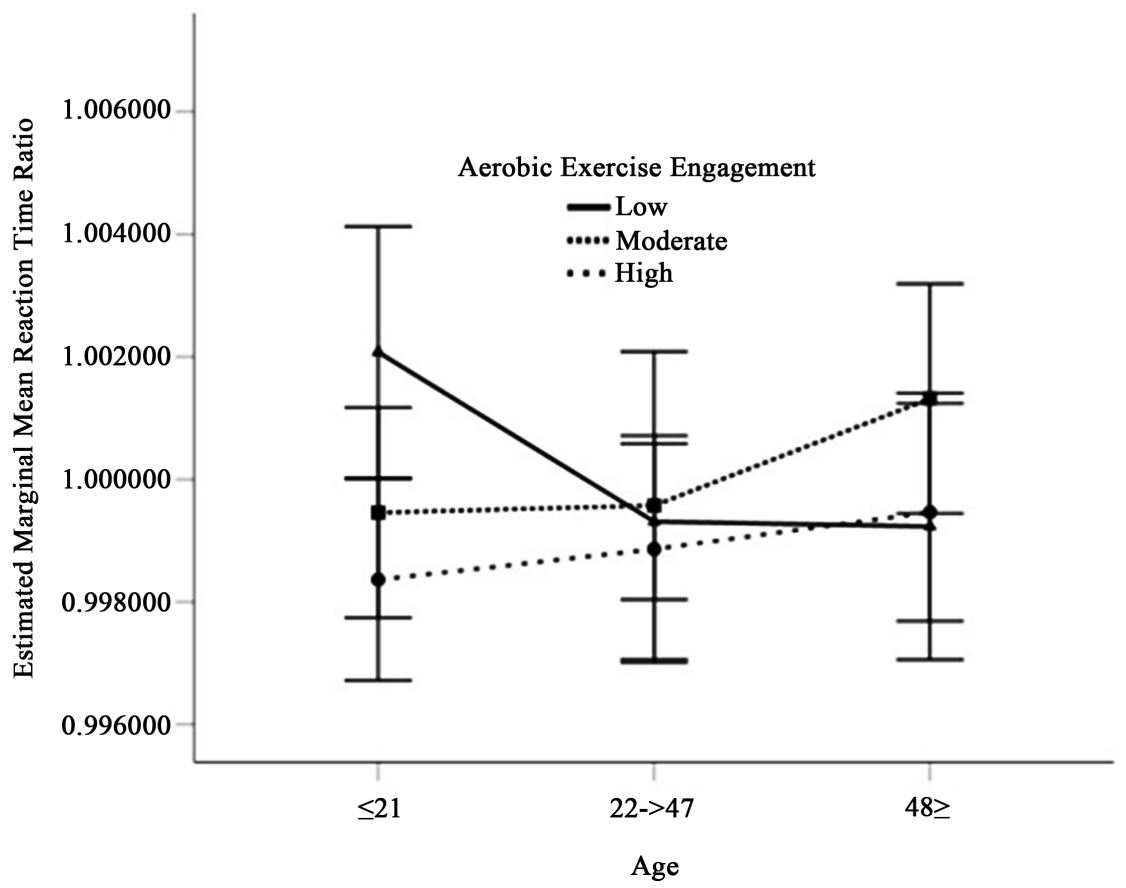

Figure 3. Mean reaction time ratio by age group, and aerobic exercise level. NB: Error bars $=95 \%$ Confidence Intervals (CI).

Reaction Time between older adults $(M=1.00, S D=0.00)$ and middle-aged, or younger adults. At moderate levels of Aerobic Exercise Engagement, no significant multivariate effect of Age was found, $F(2,12)=0.99, p=0.470$. At high levels of Aerobic Exercise Engagement, results revealed a significant multivariate effect of Age, accounting for $33 \%$ of the variation in Mental Flexibility, $F(8,38)$ $=2.35, p=0.037, \eta_{\text {partial }}^{2}=0.33$, power $=0.81$. At the univariate level, a significant effect of Age on Perseveration was found, accounting for $43 \%$ of the variance in Perseverative Error, $F(2,22)=8.36, p=0.002, \eta_{\text {partial }}^{2}=0.43$, power $=0.94$. Older adults $(M=14.50, S D=5.32)$ had significantly more Perseverative Error than younger adults $(M=3.38, S D=6.37)$ and middle-aged adults $(M=5.00, S D=$ 3.46). There was no significant difference between middle-aged and younger adults.

Moreover, as seen in Figure 4, a significant univariate effect of Age on Problem Solving Inefficiency was also found for those who engaged in high levels of Aerobic Exercise, $F(2,22)=4.88, p=0.018, \eta_{\text {partial }}^{2}=0.31$, power $=0.75$. Age accounted for $31 \%$ of the variance, with older adults $(M=0.58, S D=5.70)$ exhibiting significantly more Problem-Solving Inefficiency than younger adults $(M=$ $-8.52, S D=7.08)$. There was no significant difference between middle-aged adults $(M=-6.96, S D=2.00)$ and younger, or older adults. The effects of Age on Reaction Time Ratio, $F(2,22)=0.02, p=0.976$, and Age on Total Time Completion, $F(2,22)=0.62, p=0.548$, were non-significant.

\subsection{Age, Spatio-Temporal Tracking, and Exercise Engagement}

Results revealed no significant between-subjects effect of Age, $F(2,38)=1.69, p$ 


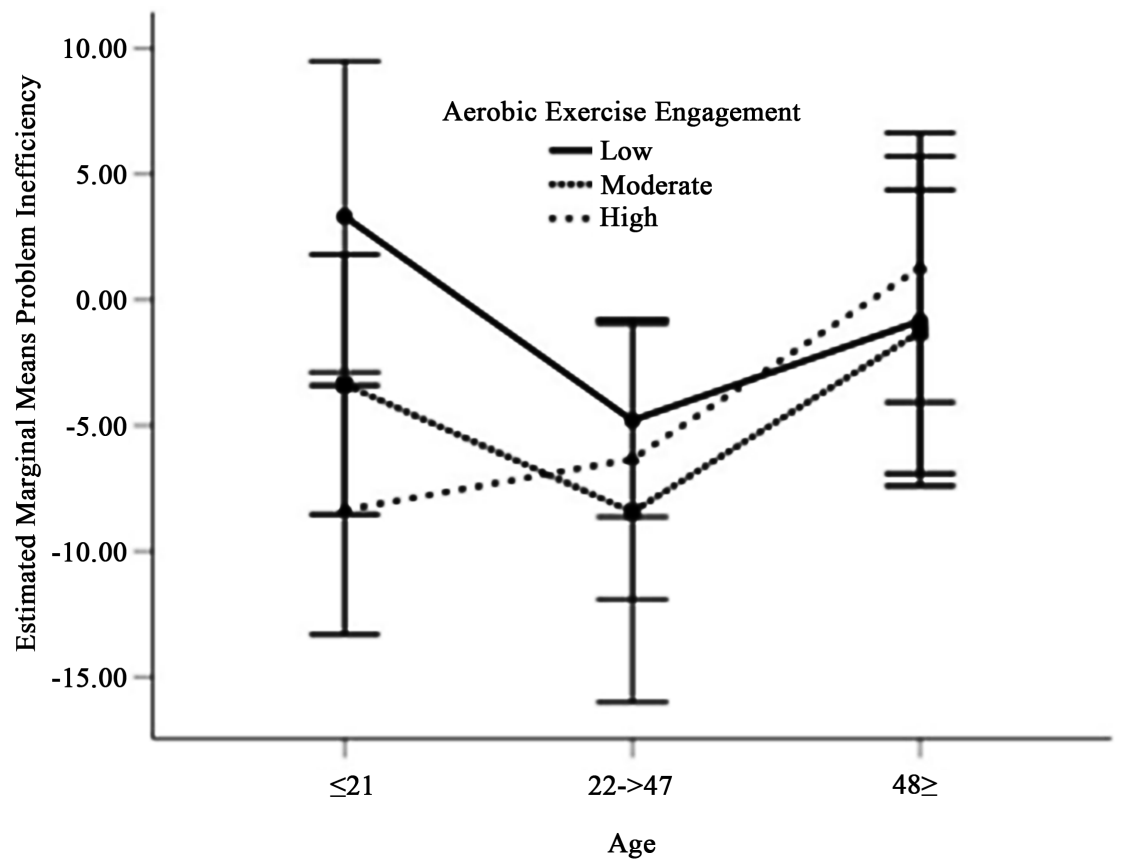

Figure 4. Mean problem-solving inefficiency by age group, and aerobic exercise level. NB: Error bars $=95 \%$ Confidence Intervals (CI).

$=0.198$, Aerobic Exercise Engagement, $F(2,38)=1.28, p=0.291$, or Resistance Exercise Engagement, $F(2,38)=1.33, p=0.277$ on the TWT outcome; Spatio-Temporal Tracking. The Age $\times$ Aerobic Exercise Engagement interaction, $F(4,38)=1.45, p=0.236$, and Age $\times$ Resistance Exercise Engagement interaction, $F(4,38)=0.37, p=0.831$, were also non-significant. There was no significant interactive effect of Aerobic Exercise Engagement $\times$ Resistance Exercise Engagement, $F(4,38)=0.25, p=0.911$, nor an Age $\times$ Resistance Exercise Engagement $\times$ Aerobic Exercise Engagement interaction, $F(1,38)=0.53, p=0.471$.

\subsection{Age Associated Cognitive Declines Detected by the BREFT}

There were no significant effects of Aerobic Exercise Engagement, $F(2,49)=$ $1.29, p=0.284$, or Resistance Exercise Engagement, $F(2,49)=0.56, p=0.574$, on BREFT EF scores. Similarly, there was no significant two-way interaction between Age and Aerobic Exercise Engagement, $F(4,49)=0.63, p=0.641$, Age and Resistance Exercise Engagement, $F(4,49)=1.50, p=0.217$, or Resistance Exercise Engagement and Aerobic Exercise Engagement, $F(4,49)=0.42, p=0.793$. Finally, the three-way interaction between Age, Resistance Exercise Engagement and Aerobic Exercise Engagement also failed to obtain significance, $F(3,49)=$ $0.86, p=0.470$. There was, however, a significant between-subjects effect of Age on $\mathrm{EF}, F(2,49)=3.73, p=0.031, \eta_{\text {partial }}^{2}=0.13$, power $=0.66$, accounting for $13 \%$ of the variance in total EF. The simple main effect of Age on EF Impairment was investigated using Tukey's HSD pos-hoc comparisons test, with results highlighting that older adults $(M=-10.44, S D=10.23)$ had significantly poorer EF than younger adults $(M=7.04, S D=14.18)$. Older adults also reported poorer 
EF compared to middle-aged adults $(M=2.36, S D=13.98)$. No significant difference between middle-aged and younger adults was observed.

\subsection{Mental Flexibility and Spatio-Temporal Tracking Performance Dissociation}

To assess for age-related dissociation between Mental Flexibility and Spatio-Temporal Tracking, a 2 (Task Type: TMT, TWT) $\times 3$ (Age: young, middle-aged, older) mixed factorial MANOVA was conducted. Age and Task Type were entered as independent variables. To allow for a reliable comparison of performance across two tasks that use different metrics, TWT average Inaccuracy scores and TMT Perseverative Error scores were standardized to $(Z)$ scores and entered as composite dependent variables. The multivariate Task Type $\times$ Age interaction was significant, indicating that EF performance varied as a function of Age and Task Type, $F(2,53)=6.61, p=0.003, \eta_{\text {partial }}^{2}=0.20$, power $=0.90$. The main effect of Task Type was non-significant, $F(1,53)=0.25, p=0.618$, as was the between-subjects effect of Age, $F(2,53)=1.06, p=0.354$. To unpack the significant interaction, the file was split by Age. For younger participants, there was no significant effect of Task Type, $F(1,22)=0.20, p=0.657$. Similarly, for middle-aged participants, EF performance did not vary by Task Type, $F(1,15)$, = 4.39, $p=0.054$. For older-aged participants, however, there was a significant effect of Task Type, accounting for $27 \%$ of the variance in EF performance, $F(1$, $16)=5.78, p=0.029, \eta_{\text {partial }}^{2}=0.27$, power $=0.62$. As can be seen in Figure 5, older-aged adults" Perseverative Error on the TMT task $(M=0.49, S D=1.19)$ was significantly higher than their TWT Inaccuracy $(M=-0.30, S D=0.60)$.

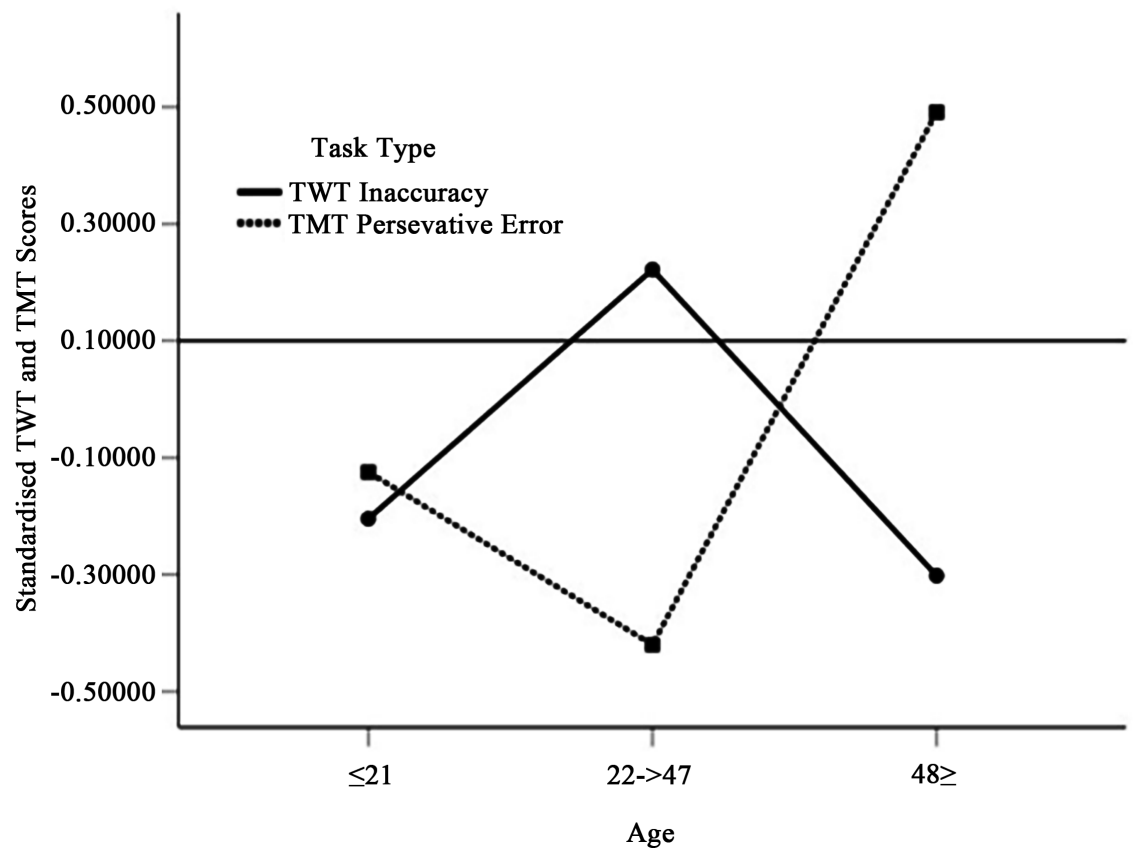

Figure 5. Z of TWT inaccuracy and TMT perseverative Error, by age group. NB: The reference line indicates grand mean level of EF performance. 


\section{Discussion}

The primary aim of the current study was to conduct a cross-sectional examination of the relationship between age, aerobic and resistance exercise engagement on EF performance. An additional aim was to add to the theoretical body of literature addressing whether cognitive functions decline at the same rate (generalized), or at varying rates within sub-systems (modular). As hypothesized, results revealed a significant effect of age on the EF behavioural checklist; the BREFT. Aligning with previous literature suggesting that EF declines with age (Healey et al., 2008; Karlamangla et al., 2017; Schroeder \& Salthouse, 2004; Uttl, 2008), older adults $(48+$ years old) reported the most EF impairment, followed by middle-aged (22 - 47 years old), and younger adults (18 - 21 years old). The significant difference between middle-aged and younger adults gives credence to Salthouse's (2011) commentary that cognition begins to decline in early to middle adulthood, as opposed to age 60 and beyond. Contrary to the current study's predictions, there was no effect of aerobic or resistance exercise on self-reported EF impairment. It's plausible to suggest that the BREFT may be insensitive to exercise-induced effects. Despite this, given that the BREFT appears to detect age-associated EF performance discrepancies, further investigation into its psychometric properties are recommended. Considering that treatment is fundamentally ineffective once dementia has onset (Lamb et al., 2018), a future project should also consider administering the BREFT to a clinical sample, potentially validating its use as a sensitive diagnostic tool for detecting early-onset pathological EF deficits. Such advances would aid significantly in alleviating an already overburdened health care system (Christie et al., 2017).

Contrary to the hypothesis, mental flexibility (reaction time, total time completion, problem solving efficiency and perseverative error) did not differ across age cohorts. This is inconsistent with previous literature suggesting TMT performance declines with age (Ashendorf et al., 2008; Piper et al., 2012; Rasmusson et al., 1998). One explanation for this discrepancy points to potential differences in motivation and selective engagement as a function of age. As noted by Perfect and Lindsay (2013), older adults are more likely to perceive a social contract between themselves and the experimenter. Attention to the personal value of task outcomes has also been found to increase with age. Older adults are more fearful of cognitive decline, subsequently increasing their motivation to perform (Germain \& Hess, 2007; Hess, Germain, Swaim, \& Osowski, 2009). In addition, spatio-temporal tracking in the current study remained preserved with age concordant with previous findings (Piper et al., 2012, 2015; Roudaia \& Faubert, 2017, Wearden et al., 1997).

The current study also hypothesized that, at low levels of aerobic exercise engagement older adults would exhibit poorer mental flexibility, compared to their younger counterparts. With increasing amounts of aerobic exercise, however, it was expected that these age-associated discrepancies would dissipate. Results partially supported this hypothesis. At low levels of aerobic engagement, older 
adults displayed more perseverative errors and evidenced slower reaction times than middle-aged participants. This was consistent with research indicating that mental flexibility impairments tend to emerge in early to middle adulthood (Schroeder \& Salthouse, 2004). There was no difference in perseverative error or reaction time, however, when comparing younger and older participants. It may be the case that younger participants in the current study were less motivated to optimally perform on the TMT (Perfect \& Lindsay, 2013). Caution should be taken when interpreting this result, however, due to insufficient cell sizes in the low aerobic engagement cells due to the limited sample size and bias (i.e., $n=6$; Tabachnick \& Fidell, 2013). Preliminary analyses indicated that $96 \%$ of older adults engaged in at least one episode of aerobic exercise in the past month. Given that research suggests approximately $22 \%$ of older Australian adults (50+) are entirely inactive (Adair, 2015), the study's sample appears to be unrepresentative of the general Australian population due to restriction of range within exercise engagement variables. This shortcoming attests to the special challenges inherent in recruiting a sample of seniors for psychological research (Chase, 2013). For future cross-sectional designs, researchers should consider alternative sampling strategies (i.e., direct random stratified sampling) to ensure the inclusion of participants ranging from highly active, to fully sedentary.

At moderate aerobic engagement levels, there were no significant age-associated differences in mental flexibility. Similarly, at high levels of aerobic exercise engagement, reaction time on the TMT no longer varied between age groups. These findings are consistent with previous literature indicating preservation of function as a result of increased aerobic exercise engagement (Smith et al., 2010; Vaportzis et al., 2019). This evidence also provides tentative support for the implementation of moderate to high levels of aerobic exercise for buffering against age-related declines in mental flexibility. It should be noted, however, that aerobic exercise accounted for only a small proportion of the variance in EF. Thus, along with the recruitment of a larger, more diverse sample, additional factors for buffering against mental flexibility declines should also be considered. For example, older adults who report engaging in regular exercise also show more participation in social activities and are less prone to unhealthy lifestyles - both concepts that require further exploration (Fabel \& Kempermann, 2008; Jedrziewski, Ewbank, Wang, \& Trojanowski, 2014). Contrary to previous literature reporting that high levels of aerobic training are associated with improvements in task-switching ability (Coetsee \& Tablanche, 2017; Vaportzis et al., 2019), older adults with high aerobic engagement exhibited more perseverative errors and problem-solving inefficiencies than their younger counterparts. Higher aerobic engagement may cause fatigue effects that induce poorer performance in the elderly; analogous to evidence indicating that elite athletes are more susceptible to immune dysfunction via training overload (Young et al., 2015; Walsh, 2018). It is therefore possible that high levels of aerobic exercise engagement may not necessarily be optimal for buffering against age-related cognitive declines. 
The study also hypothesized that at lower levels of resistance exercise, older participants would exhibit poorer mental flexibility, compared to middle-aged and younger participants. This hypothesis was partially supported. At low levels of resistance training, older adults displayed more perseverative error on the TMT; a finding consistent with prior literature (Mueller \& Piper, 2014; Piper et al., 2012). Also consistent with previous literature (Liu-Ambrose et al., 2012), at moderate levels of resistance exercise engagement perseverative error did not significantly differ across age cohorts. This highlighted what appears to be a benefit of moderate resistance exercise for buffering against age related decline in mental flexibility. It should be noted, however, that to allow for equivalence of cell sizes across the three resistance exercise levels, cut off points were defined by a natural break. As a result, age by resistance exercise cross tabulations revealed that some cells were considerably small (Tabachnick \& Fidell, 2013). It has been noted by Tutfe (1990) that tunneling down data often renders cells with less than five cases uninterpretable, an assertion that can be applied to the result in question. Exploratory multiple regression analysis is recommended for future studies to avoid the discretisation of underlying continuous data.

Contrary to expectations, higher resistance exercise engagement did not predict the dissipation of age-related differences in perseverative error. Older adults exhibited greater perseverative error than their middle-aged and younger counterparts; consistent with Chang and Etnier (2009) who found a benefit of high resistance training for selective attention, but not mental flexibility or processing speed. This finding also corroborated with Cassilhas et al.'s (2007) conclusions that there is no additional benefit of high resistance exercise engagement beyond that of moderate levels. As noted by previous researchers who failed to find a cognitive benefit of increasing resistance exercise (Alves et al., 2012; Kimura et al., 2013; Ruiz et al., 2015), it is possible that the current study's participants had not exercised for long enough to reap cognitive reserve benefits. Similarly, there is also evidence to suggest that only high intensity resistance exercise training can enhance BDNF amongst older adults the mechanism by which resistance exercise is thought to benefit cognition (Goldfield et al., 2018). The current study's scope did not allow for a viable assessment of participants" exercise intensity. Thus, it is possible that the average level of intensity was insufficient to elicit remarkable improvements in cognitive performance.

Given the absence of a reliable and valid retrospective measure of exercise engagement appropriate for the study in question, breaking the existing RPAQ was necessary. This allowed for the collection of data pertaining to participant's aerobic and resistance exercise engagement, separately. With a small sample size, emphasis was placed upon assuring reasonable equivalence of cell sizes. Thus, the amounts of exercise engagement constituting low, moderate, and high levels were determined by histogram distributions; ensuring that each group had enough data to conduct a robust MANOVA (Tabachnick \& Fidell, 2013). As a result, dose-parameters may not reliably distinguish between low, moderate, and high levels of exercise, nor coincide with definitions in extant research. To im- 
prove the RPAQ-R, it is recommended that a panel review be conducted. Ideally, this panel should include experts (i.e., exercise physiologists) who can more reliably establish a fixed criterion to discriminate between aerobic and resistance exercise activity, as well as define valid metrics corresponding to low, moderate and high resistance engagement in the general Australian population. Including measures of exercise intensity and duration may also give rise to a more detailed explanation of the interplay between differential exercise dose-parameters and cognitive impairment across the lifespan.

Although using retrospective self-report exercise questionnaires is inexpensive and has low participant burden (Rennie \& Wareham, 1998), the inability to draw causal inference (Althubaiti, 2016) raises the question as to whether specific aerobic and resistance exercise dosages predict slowed cognitive decline, or are merely symptoms that result from a slowing in cognition function? Thus, an alternative option for future researchers is to conduct a conceptual replication of the current study, by employing a true experimental longitudinal design. A methodology like that used in Anderson-Hanley et al.'s (2010) study is recommended. Matched participants engage in one to two months of controlled, high intensity exercise, with pre, mid, and post-test measures of cognitive functionality. Where feasible, objective measures of cardiorespiratory fitness gains (i.e., VO2max), cerebral blood flow (i.e., fMRI), BDNF (i.e., plasma) and inflammation (i.e., CRP) would also allow for a deeper understanding of the mechanisms by which specific exercise parameters may influence cognitive aging (Barnes et al., 2003; Horder et al., 2018; Muscari et al., 2010). Of course, longitudinal research is not without its pitfalls. Careful consideration must be given to the possibility of attrition and practise effects misleadingly manifesting as maturation or a lack thereof (Salthouse, 2009).

Furthermore, in line with research supporting the modular model of cognitive aging (Alexander, Bahr, \& Hicks, 2014; Geerligs et al., 2014), the hypothesised dissociative relationship between mental flexibility and spatio-temporal tracking performance was supported. For older participants, perseverative error on the TMT was significantly greater than inaccuracy on the TWT consistent with emerging research suggesting that mental flexibility declines with age, yet spatio-temporal tracking is preserved (Ashendorf et al., 2008; Piper et al., 2012; Roudaia \& Faubert, 2017; Salthouse, 1996, 2009). As the current study suggests, if cognitive aging is modular, intervention strategies tailored towards preserving modules that are more susceptible to senescence may be beneficial for increasing the likelihood of older adults remaining cognitively apt well into their later years.

\section{Implications and Conclusion}

Despite limitations, the current study has several significant implications. Notably, given the dramatic discrepancies among empirical studies investigating the course and timing of age-related cognitive decline, this project has added to the existing body of theoretical literature offering valuable insight into the process of 
cognitive aging. Specifically, the results aid in clarifying question as to whether the aging brain declines variably across cognitive subsystems or in a globalized fashion due to organic influence. As such, it appears that cognitive decline typically emerges around middle-age and is asynchronous in nature. Thus, with additional validation and replication, cognitive reserve behavioural intervention should be tailored in attempt to maintain cognitive functions that are more susceptible to senescence. The study corroborates with existing literature highlighting that EF ability declines with increasing age and therefore may be a potentially useful marker for screening early cognitive ageing disease onset (Harada, et al., 2013). Moreover, results also provide relatively novel evidence demonstrating that spatio-temporal tracking abilities in older adults may remain in-tact. This significant difference in cognitive performance across two cognitive domains helps to inform specific early intervention strategies. Additionally, the study has advanced extant literature by developing a retrospective questionnaire differentiating types of exercise. Although the exercise question warrants considerable revision regarding the differentiation of low, moderate and high aerobic and resistance exercise, the RPAQ- $R$ is the first of its kind that attempts to retrospectively measure exercise engagement including everyday activities distributed by aerobic and resistance criterions. Similarly, a novel and potentially clinically useful measure of age-associated EF impairment has also been preliminarily validated in this project. With further use and validation, the development of this test contributes towards more feasible and time-efficient screening of EF age-associated deficits in clinical settings. Given that traditional tests are typically found to have poor sensitivity and specificity for detecting cognitive declines (i.e., the MMSE; Spencer et al., 2013), the BREFT may also exhibit more sound psychometric properties necessary for a reliable measurement of cognitive domain functioning among older adults. The current study's multi-factorial operation of executive function also accounted for two limitations in cognitive ageing literature: mono-operation bias and poor construct validity for measuring several cognitive domains. By using two sensitive neuropsychologial tests (TMT and TWT), as well as a self-report executive function behavioural checklist to investigate executive function, this limitation was addressed.

Ultimately, this study supports the implementation of moderate to high aerobic and moderate resistance exercise intervention for enhancing the mental flexibility of older adults. Given that exercise behaviour declines profoundly as adults age (Adair, 2015; Milanovic et al., 2013), these findings could contribute to health promotion and educational material aiming to reiterate the importance of staying active (with both aerobic and resistance engagement) to maintain intact fluid cognition. Continual research into the benefits of exercise dose-parameters for enhancing cognitive reserve among older adults is necessary to determine how robust these findings are. Small batteries of standardized EF measures should be used in geriatric decline studies to combat the current issues regarding heterogeneous methodology (Snowden et al., 2011). As the proportion of the population constituted by baby-boomers bulges, the incidence of aged as- 
sociated pathological decline continues to rise (ABS, 2017; Deary et al., 2009). It is therefore imperative that geriatric researchers persist with understanding the nature of cognitive aging and additional protective factors that maintain cognitive vitality

\section{Conflicts of Interest}

The authors declare no conflicts of interest associated with the publication of this paper.

\section{References}

Aartsen, M. J., Smits, C. H. M., van Tilburg, T., Knipscheer, C. P. M., \& Deeg, D. J. H. (2002). Activity in Older Adults: Cause or Consequence of Cognitive Functioning? A Longitudinal Study on Everyday Activities and Cognitive Performance in Older Adults. Journals of Gerontology. Series B: Psychological Sciences and Social Sciences, 57, 157-162. https://doi.org/10.1093/geronb/57.2.P153

Adair, T. (2015). How Physically Active Are Senior Australians? Evidence from National Data. Melbourne: National Seniors Productive Aging Centre.

Alexander, V., Bahr, M., \& Hicks, R. (2014). Emotion Recognition and Verbal and Non-Verbal Memory Changes among Older Adults: Is Decline Generalised or Modular? GSTF Journal of Psychology, 1, 15-19. https://doi.org/10.5176/2345-7872 1.2.14

Althubaiti, A. (2016). Information Bias in Health Research: Definition, Pitfalls, and Adjustment Methods. Journal of Multidisciplinary Healthcare, 9, 211-217. https://doi.org/10.2147/JMDH.S104807

Alves, C. R., Gualano, B., Takao, P. P., Avakian, P., Fernandes, R. M., Morine, D., \& Takito, M. Y. (2012). Effects of Acute Physical Exercise on Executive Functions: A Comparison between Aerobic and Strength Exercise. Journal of Sport \& Exercise Psychology, 34, 539-549. https://doi.org/10.1123/jsep.34.4.539

Anderson-Hanley, C., Nimon, J. P., \& Westen, S. C. (2010). Cognitive Health Benefits of Strengthening Exercise for Community-Dwelling Older Adults. Journal of Clinical and Experimental Neuropsychology, 32, 996-1001. https://doi.org/10.1080/13803391003662702

Ashby-Mitchell, K., Burns, R., Shaw, J., \& Anstey, K. J. (2017). Proportion of Dementia in Australia Explained by Common Modifiable Risk Factors. Alzheimer's Research \& Therapy, 9, 11. https://doi.org/10.1186/s13195-017-0238-x

Ashendorf, L., Jefferson, A. L., O'Connor, M. K., Chaisson, C., Green, R. C., \& Stern, R. A. (2008). Trail Making Test Errors in Normal Aging, Mild Cognitive Impairment, and Dementia. Archives of Clinical Neuropsychology, 23, 129-137. https://doi.org/10.1016/j.acn.2007.11.005

Australian Bureau of Statistics (2017). Causes of Death, Australia, 2017 (Catalogue No. 3303.0). https://www.abs.gov.au

Bailey, E. (2018). Could You Have Executive Function Deficit? https://www.additudemag.com

Barnes, D. E., Yaffe, K., Satariano, W. A., \& Tager, I. B. (2003). A Longitudinal Study of Cardiorespiratory Fitness and Cognitive Function in Healthy Older Adults. Journal of the American Geriatrics Society, 51, 459-465.

https://doi.org/10.1046/j.1532-5415.2003.51153.x

Birren, J. E. (1964). The Psychology of Aging. Oxford, England: Prentice Hall. 
Blacker, D., Lee, H., Muzikansky, A., Martin, E. C., Tanzi, R., McArdle, J. J., \& Albert, M. (2007). Neuropsychological Measures in Normal Individuals that Predict Subsequent Cognitive Decline. Archives of Neurology, 64, 862-871. https://doi.org/10.1001/archneur.64.6.862

Boyle, P. A., Wilson, R. S., Yu, L., Barr, A. M., Honer, W. G., Schneider, J. A., \& Bennett, D. A. (2013). Much of Late Life Cognitive Decline Is Not Due To Common Neurodegenerative Pathologies. Annals of Neurology, 74, 478-489.

https://doi.org/10.1002/ana.23964

Brown, B. M., Peiffer, J. J., Taddei, K., Lui, J. K., Laws, S. M., Gupta, V. B., \& Martins, R. N. (2013). Physical Activity and Amyloid-B Plasma and Brain Levels: Results from the Australian Imaging, Biomarkers and Lifestyle Study of Aging. Molecular Psychiatry, 18, 875-881. https://doi.org/10.1038/mp.2012.107

Cassilhas, R. C., Viana, V. A. R., Grassmann, V., Santos, R. T., Santos, R. F., Tufik, S., \& Mello, M. T. (2007). The Impact of Resistance Exercise on the Cognitive Function of the Elderly. Medicine and Science in Sports and Exercise, 39, 1401-1407. https://doi.org/10.1249/mss.0b013e318060111f

Celidoni, M., Dal Bianco, C., \& Weber, G. (2017). Retirement and Cognitive Decline. A Longitudinal Analysis Using SHARE Data. Journal of Health Economics, 56, 113-125. https://doi.org/10.1016/j.jhealeco.2017.09.003

Chang, Y., \& Etnier, J. L. (2009). Exploring the Dose-Response Relationship between Resistance Exercise Intensity and Cognitive Function. Journal of Sport \& Exercise Psychology, 31, 640-656. https://doi.org/10.1123/jsep.31.5.640

Chase, J. D. (2013). Methodological Challenges in Physical Activity Research with Older Adults. Western Journal of Nursing Research, 35, 76-97. https://doi.org/10.1177/0193945911416829

Chaytor, N., Schmitter-Edgecombe, M., \& Burr, R. (2006). Improving the Ecological Validity of Executive Functioning Assessment. Archives of Clinical Neuropsychology, 21, 217-227. https://doi.org/10.1016/j.acn.2005.12.002

Christie, G. J., Hamilton, T., Manor, B. D., Farb, N. A. S., Farzan, F., Sixsmith, A., \& Moreno, S. (2017). Do Lifestyle Activities Protect against Cognitive Decline in Aging? A Review. Frontiers in Aging Neuroscience, 9, 381.

https://doi.org/10.3389/fnagi.2017.00381

Clark, L. R., Schiehser, D. M., Weissberger, G. H., Salmon, D. P., Delis, D. C., \& Bondi, M. W. (2012). Specific Measures of Executive Function Predict Cognitive Decline in Older Adults. Journal of the International Neuropsychological Society, 18, 118-127. https://doi.org/10.1017/S1355617711001524

Coetsee, C., \& Terblanche, E. (2017). The Effect of Three Different Exercise Training Modalities on Cognitive and Physical Function in a Healthy Older Population. European Review of Aging and Physical Activity: Official Journal of the European Group for Research into Elderly and Physical Activity, 14, 13-19. https://doi.org/10.1186/s11556-017-0183-5

Correia, S., Ahern, D. C., Rabinowitz, A. R., Farrer, T. J., Smith Watts, A. K., Salloway, S., \& Deoni, S. C. L. (2015). Lowering the Floor on Trail Making Test Part B: Psychometric Evidence for a New Scoring Metric. Archives of Clinical Neuropsychology: The Official Journal of the National Academy of Neuropsychologists, 30, 643-656. https://doi.org/10.1093/arclin/acv040

Cosentino, S., Stern, Y., Sokolov, E., Scarmeas, N., Manly, J., Tang, M. X., \& Mayeux, R. (2010). Plasma Amyloid B Predicts Cognitive Decline. Archives of Neurology, 67, 1485-1490. https://doi.org/10.1001/archneurol.2010.189 
Cotman, C. W., \& Berchtold, N. C. (2002). Exercise: A Behavioural Intervention to Enhance Brain Health and Plasticity. Trends in Neurosciences, 25, 295-301. https://doi.org/10.1016/S0166-2236(02)02143-4

Cronbach, L. J. (1951). Coefficient Alpha and the Internal Structure of Tests. Psychometrika, 16, 297. https://doi.org/10.1007/BF02310555

Davidson, P. S. R., Gao, F. Q., Mason, W. P., Winocur, G., \& Anderson, N. D. (2008). Verbal Fluency, Trail Making, and Wisconsin Card Sorting Test Performance Following Right Frontal Lobe Tumor Resection. Journal of Clinical and Experimental Neuropsychology, 30, 18-32. https://doi.org/10.1080/13803390601161166

Deary, I. J., Corley, J., Gow, A. J., Harris, S. E., Houlihan, L. M., Marioni, R. E., \& Starr, J. M. (2009). Age-Associated Cognitive Decline. British Medical Bulletin, 92, 135-152. https://doi.org/10.1093/bmb/ldp033

Demakis, G. J. (2003). A Meta-Analytic Review of the Sensitivity of the Wisconsin Card Sorting Test to Frontal and Lateralized Frontal Brain Damage. Neuropsychology, 17, 255-264. https://doi.org/10.1037/0894-4105.17.2.255

Doblhammer, G., van den Berg, G. J, \& Fritze, T. (2013). Economic Conditions at the Time of Birth and Cognitive Abilities Late in Life: Evidence from Ten European Countries. PLoS ONE, 8, 749-755. https://doi.org/10.1371/journal.pone.0074915

Donohue, M. C., Sperling, R. A., Petersen, R., Sun, C., Weiner, M. W., \& Aisen, P. S. (2017). Association between Elevated Brain Amyloid and Subsequent Cognitive Decline among Cognitively Normal Persons. The Journal of the American Medical Association, 317, 2305-2316. https://doi.org/10.1001/jama.2017.6669

Etnier, J. L., Nowell, P. M., Landers, D. M., \& Sibley, B. A. (2006). A Meta-Regression to Examine the Relationship between Aerobic Fitness and Cognitive Performance. Brain Research Reviews, 52, 119-130. https://doi.org/10.1016/j.brainresrev.2006.01.002

Fabel, K., \& Kempermann, G. (2008). Physical Activity and the Regulation of Neurogenesis in the Adult and Aging Brain. NeuroMolecular Medicine, 10, 59-66. https://doi.org/10.1007/s12017-008-8031-4

Falck, R. S., Davis, J. C., Best, J. R., Crockett, R. A., \& Liu-Ambrose, T. (2019). Impact of Exercise Training on Physical and Cognitive Function among Older Adults: A Systematic Review and Meta-Analysis. Neurobiology of Aging, 79, 119-130. https://doi.org/10.1016/j.neurobiolaging.2019.03.007

Faul, F., Erdfelder, E., Lang, A. G., \& Buchner, A. (2007). G*Power 3: A Flexible Statistical Power Analysis Program for the Social, Behavioural, and Biomedical Sciences. Behaviour Research Methods, 39, 175-191. https://doi.org/10.3758/BF03193146

Feng, L., Ng, X., Yap, P., Li, J., Lee, T., Håkansson, K., \& Ng, T. (2014). Marital Status and Cognitive Impairment among Community-Dwelling Chinese Older Adults: The Role of Gender and Social Engagement. Dementia and Geriatric Cognitive Disorders Extra, 4, 375-384. https://doi.org/10.1159/000358584

Folstein, M. F., Folstein, S. E., \& McHugh, P. R. (1975). Mini-Mental State. A Practical Method for Grading the Cognitive State of Patients for the Clinician. Journal of Psychiatric Research, 12, 189-198. https://www.ncbi.nlm.nih.gov https://doi.org/10.1016/0022-3956(75)90026-6

Foverskov, E., Glymour, M. M., Mortensen, E. L., Holm, A., Lange, T., \& Lund, R. (2018). Education and Cognitive Aging: Accounting for Selection and Confounding in Linkage of Data from the Danish Registry and Survey of Health, Aging and Retirement in Europe. American Journal of Epidemiology, 187, 2423-2430.

https://doi.org/10.1093/aje/kwy162 
Gaffney, B., Roberts, C., Houx, P. J., Ward, S., Shepherd, J., Kee, F., \& Westendorp, R. G. (1995). Are The Economically Active More Deserving? Journal of Neurology, Neurosurgery \& Psychiatry, 73, 385-389. https://doi.org/10.1136/hrt.73.4.385

Geerligs, L., Renken, R. J., Saliasi, E., Maurits, N. M., \& Lorist, M. M. (2014). A Brain-Wide Study of Age-Related Changes in Functional Connectivity. Cerebral Cortex, 25, 1987-1999. https://doi.org/10.1093/cercor/bhu012

Germain, C. M., \& Hess, T. M. (2007). Motivational Influences on Controlled Processing: Moderating Distractibility in Older Adults. Aging, Neuropsychology, and Cognition, 14, 462-486. https://doi.org/10.1080/13825580600611302

Glisky, E. L., Polster, M. R., \& Routhieaux, B. C. (1995). Double Dissociation between Item and Source Memory. Neuropsychology, 9, 229-235. https://doi.org/10.1037/0894-4105.9.2.229

Godefroy, O., Roussel, M., Despretz, P., Quaglino, V., \& Boucart, M. (2010). Age-Related Slowing: Perceptuomotor, Decision, or Attention Decline? Experimental Aging Research, 36, 169-189. https://doi.org/10.1080/03610731003613615

Gold, B. T. (2015). Lifelong Bilingualism and Neural Reserve against Alzheimer's Disease: A Review of Findings and Potential Mechanisms. Behavioural Brain Research, 281, 9-15. https://doi.org/10.1016/j.bbr.2014.12.006

Goldberg, T., Harvey, P., Wesnes, K., Synder, P., \& Schneider, L. (2015). Practice Effects Due to Serial Cognitive Assessment: Implications for Preclinical Alzheimer's Disease Randomized Controlled Trials. Alzheimer's \& Dementia: Diagnosis, Assessment \& Disease Monitoring, 1, 103-111. https://doi.org/10.1016/j.dadm.2014.11.003

Goldfield, G. S., Kenny, G. P., Prud'homme, D., Holcik, M., Alberga, A. S., Fahnestock, M., \& Sigal, R. J. (2018). Effects of Aerobic Training, Resistance Training, or Both on Brain-Derived Neurotrophic Factor in Adolescents with Obesity: The Hearty Randomized Controlled Trial. Physiology \& Behaviour, 191, 138-145.

https://doi.org/10.1016/j.physbeh.2018.04.026

Golubic R., May, A. M., Benjaminsen, B. K., Overvad, K., Charles, M. A., Diaz, M. J., \& Brage, S. (2014). Validity of Electronically Administered Recent Physical Activity Questionnaire (RPAQ) in Ten European Countries. PLoS ONE, 9, 114-118. https://doi.org/10.1371/journal.pone.0092829

Harada, C. N., Natelson Love, M. C., \& Triebel, K. L. (2013). Normal Cognitive Aging. Clinics in Geriatric Medicine, 29, 737-752. https://doi.org/10.1016/j.cger.2013.07.002

Harvey, P. D., \& Bowie, C. R. (2006). Administration and Interpretation of the Trail Making Test. Nature Protocols, 1, 2277-2281. https://doi.org/10.1038/nprot.2006.390

Head, D., Kennedy, K. M., Rodrigue, K. M., \& Raz, N. (2009). Age Differences in Perseveration: Cognitive and Neuroanatomical Mediators of Performance on The Wisconsin Card Sorting Test. Neuropsychologia, 47, 1200-1203. https://doi.org/10.1016/j.neuropsychologia.2009.01.003

Healey, M. K., Campbell, K. L., \& Hasher, L. (2008). Chapter 22 Cognitive Aging and Increased Distractibility: Costs and Potential Benefits. Progress in Brain Research, 169, 353-363. https://doi.org/10.1016/S0079-6123(07)00022-2

Helmes, E., \& Harris, S. (2017). Exercise and Executive Functioning in Older Women. Journal of Women \& Aging, 29, 376-384. https://doi.org/10.1080/08952841.2016.1256736

Herold, F., Törpel, A., Schega, L., \& Müller, N. G. (2019). Functional and/or Structural Brain Changes in Response to Resistance Exercises and Resistance Training Lead to Cognitive Improvements: A Systematic Review. European Review of Aging and Physical Activity, 16, 1-18. https://doi.org/10.1186/s11556-019-0217-2 
Hess, T. M., Germain, C. M., Swaim, E. L., \& Osowski, N. L. (2009). Aging and Selective Engagement: The Moderating Impact of Motivation on Older Adults' Resource Utilization. Journals of Gerontology Series B: Psychological Sciences and Social Sciences, 64, 447-456. https://doi.org/10.1093/geronb/gbp020

Horder, H., Johansson, L., Guo, X., Grimby, G., Kern, S., Östling, S., \& Skoog, I. (2018). Midlife Cardiovascular Fitness and Dementia: A 44-Year Longitudinal Population Study in Women. Neurology, 90, 1298-1305.

https://doi.org/10.1212/WNL.0000000000005290

Houtzager, N., Lowie, W., Sprenger, S., \& de Bot, C. (2017). A Bilingual Advantage in Task Switching? Age-Related Differences between German Monolinguals Anddutch-Frisian Bilinguals. Bilingualism: Language and Cognition, 20, 69-79. https://doi.org/10.1017/S1366728915000498

Jacobson, S. C., Blanchard, M., Connolly, C. C., Cannon, M., \& Garavan, H. (2011). An FMRI Investigation of a Novel Analogue to the Trail-Making Test. Brain and Cognition, 77, 60-70. https://doi.org/10.1016/j.bandc.2011.06.001

Jedrziewski, M. K., Ewbank, D. C., Wang, H., \& Trojanowski, J. Q. (2014). The Impact of Exercise, Cognitive Activities, and Socialization on Cognitive Function. American Journal of Alzheimer's Disease \& Other Dementias, 29, 372-378.

https://doi.org/10.1177/1533317513518646

Kaiser, H. F. (1974). An Index of Factorial Simplicity. Psychometrika, 39, 31-34. https://doi.org/10.1007/BF02291575

Karlamangla, A. S., Lachman, M. E., Han, W., Huang, M., \& Greendale, G. A. (2017). Evidence for Cognitive Aging in Midlife Women: Study of Women's Health across The Nation. PLoS ONE, 12, 169. https://doi.org/10.1371/journal.pone.0169008

Kimura, K., Yasunaga, A., \& Wang, L. (2013). Correlation between Moderate Daily Physical Activity and Neurocognitive Variability in Healthy Elderly People. Archives of Gerontology and Geriatrics, 56, 109-117. https://doi.org/10.1016/j.archger.2012.10.004

Klencklen, G., Després, O., \& Dufour, A. (2011). What Do We Know about Aging and Spatial Cognition? Reviews and Perspectives. Aging Research Reviews, 11, 123-135. https://doi.org/10.1016/j.arr.2011.10.001

Knopman, D. S., Gottesman, R. F., Sharrett, A. R., Tapia, A. L., DavisThomas, S., Windham, B. G., \& Mosley, T. H. (2018). Midlife Vascular Risk Factors and Midlife Cognitive Status in Relation to Prevalence of Mild Cognitive Impairment and Dementia in Later Life: The Atherosclerosis Risk in Communities Study. Alzheimer's \& Dementia: The Journal of the Alzheimer's Association, 14, 1406-1415. https://doi.org/10.1016/j.jalz.2018.03.011

Komulainen, P., Pedersen, M., Hänninen, T., Bruunsgaard, H., Lakka, T. A., Kivipelto, M., \& Rauramaa, R. (2008). BDNF Is a Novel Marker of Cognitive Function in Aging Women: The DR's EXTRA Study. Neurobiology of Learning and Memory, 90, 596-603. https://doi.org/10.1016/j.nlm.2008.07.014

Kopp, B., Rösser, N., Tabeling, S., Stürenburg, H. J., de Haan, B., Karnath, H., \& Wessel, K. (2015). Errors on The Trail Making Test Are Associated with Right Hemispheric Frontal Lobe Damage in Stroke Patients. Behavioural Neurology, 15, 309-315. https://doi.org/10.1155/2015/309235

Kramer, A., \& Willis, S. L. (2002). Enhancing the Cognitive Vitality of Older Adults. Current Directions in Psychological Science, 11, 173-177. https://doi.org/10.1111/1467-8721.00194

Labelle, V., Bosquet, L., Mekary, S., Vu, T. T. M., Smilovitch, M., \& Bherer, L. (2014). Fitness Level Moderates Executive Control Disruption during Exercise Regardless of 
Age. Journal of Sport \& Exercise Psychology, 36, 258-270. https://doi.org/10.1123/jsep.2013-0115

Lamb, S. E., Sheehan, B., Atherton, N., Nichols, V., Collins, H., Mistry, D., \& Lall, R. (2018). Dementia and Physical Activity (DAPA) Trial of Moderate to High Intensity Exercise Training for People with Dementia: Randomised Controlled Trial. British Medical Journal, 361, 1675. https://doi.org/10.1136/bmj.k1675

Landrigan, J., Bell, T., Crowe, M., Clay, O. J., \& Mirman, D. (2019). Lifting Cognition: A Meta-Analysis of Effects of Resistance Exercise on Cognition. Psychological Research, 340, 1-17. https://doi.org/10.1007/s00426-019-01145-x

Latorre-Roman, P. A., Laredo-Aguilera, J. A., García-Pinillos, F., Soto-Hermoso, V. M., \& Carmona-Torres, J. M. (2018). Physical Activity, Weight and Functional Limitations in Elderly Spanish People: The National Health Survey (2009-2014). The European Journal of Public Health, 28, 778-783. https://doi.org/10.1093/eurpub/ckx219

Liu-Ambrose, T., \& Donaldson, M. G. (2009). Exercise and Cognition in Older Adults: Is There a Role for Resistance Training Programmes? British Journal of Sports Medicine, 43, 25-27. https://doi.org/10.1136/bjsm.2008.055616

Liu-Ambrose, T., Nagamatsu, L., Voss, M., Khan, K., \& Handy, T. (2012). Resistance Training and Functional Plasticity of The Aging Brain: A 12-Month Randomized Controlled Trial. Neurobiology of Aging, 33, 1690-1698.

https://doi.org/10.1016/j.neurobiolaging.2011.05.010

Mahncke, H. W., Bronstone, A., \& Merzenich, M. M. (2006). Brain Plasticity and Functional Losses in The Aged: Scientific Bases for a Novel intervention. Progress in Brain Research, 157, 81-109. https://doi.org/10.1016/S0079-6123(06)57006-2

McCarrey, A. C., An, Y., Kitner-Triolo, M. H., Ferrucci, L., \& Resnick, S. M. (2016). Sex Differences in Cognitive Trajectories in Clinically Normal Older Adults. Psychology and Aging, 31, 166-175. https://doi.org/10.1037/pag0000070

Milanovic, Z., Pantelić, S., Trajković, N., Sporiš, G., Kostić, R., \& James, N. (2013). Age-Related Decrease in Physical Activity and Functional Fitness among Elderly Men and Women. Clinical Interventions in Aging, 8, 549-556.

https://doi.org/10.2147/CIA.S44112

Mitchell, G. F., van Buchem, M. A., Sigurdsson, S., Gotal, J. D., Jonsdottir, M. K., Kjartansson, Ó., \& Launer, L. J. (2011). Arterial Stiffness, Pressure and Flow Pulsatility and Brain Structure and Function: The Age, Gene/Environment Susceptibility-Reykjavik Study. Brain, 134, 3398-3407. https://doi.org/10.1093/brain/awr253

Mueller, S. T., \& Piper, B. J. (2014). The Psychology Experiment Building Language (PEBL) and PEBL Test Battery. Journal of Neuroscience Methods, 222, 250-259. https://doi.org/10.1016/j.jneumeth.2013.10.024

Muir, R., Lam, B., Honjo, K., Harry, R., McNeely, A., Gao, F., \& Black, S. (2015). Trail Making Test Elucidates Neural Substrates of Specific Poststroke Executive Dysfunctions. Stroke, 46, 2755-2761. https://doi.org/10.1161/STROKEAHA.115.009936

Muscari, A., Giannoni, C., Pierpaoli, L., Berzigotti, A., Maietta, P., Foschi, E., \& Zoli, M. (2010). Chronic Endurance Exercise Training Prevents Aging-Related Cognitive Decline in Healthy Older Adults: A Randomized Controlled Trial. International Journal of Geriatric Psychiatry, 25, 1055-1064. https://doi.org/10.1002/gps.2462

National Health and Medical Research Council (NHMRC) (2018). The National Statement on Ethical Conduct in Human Research. https://www.nhmrc.gov.au

Oosterman, J. M., Vogels, R. L., Harten, B. V., Gouw, A. A., Poggesi, A., Scheltens, P., \& Scherder, E. J. (2010). Assessing Mental Flexibility: Neuroanatomical and Neuropsy- 
chological Correlates of the Trail Making Test in Elderly People. Clinical Neuropsychologist, 24, 203-219. https://doi.org/10.1080/13854040903482848

Pase, M., Beiser, A., Himali, J., Tsao, C., Satizabal, C., Vasan, R., \& Mitchell, G. (2016). Aortic Stiffness and The Risk of incident Mild Cognitive Impairment and Dementia. Stroke, 47, 2256-2261. https://doi.org/10.1161/STROKEAHA.116.013508

Payne, S. L. (1980). The Art of Asking Questions. Princeton, NJ: Princeton University Press. https://doi.org/10.1515/9781400858064

Pensel, M. C., Daamen, M., Scheef, L., Knigge, H. U., Rojas Vega, S., Martin, J. A., \& Boecker, H. (2018). Executive Control Processes Are Associated with individual Fitness Outcomes Following Regular Exercise Training: Blood Lactate Profile Curves and Neuroimaging Findings. Scientific Reports, 8, 4893-4812.

https://doi.org/10.1038/s41598-018-23308-3

Perez, W. A., Masline, P. J., Ramsey, E. G., \& Urban, K. E. (1987). Unified Tri-Services Cognitive Performance Assessment Battery: Review and Methodology. Dayton, OH: Systems Research Labs. https://doi.org/10.1037/e455772004-001

Perfect, T. J., \& Lindsay, D. S. (2013). The SAGE Handbook of Applied Memory. London, UK: SAGE Publications Ltd. https://doi.org/10.4135/9781446294703

Petersen, R. C., Doody, R., Kurz, A., Mohs, R. C., Morris, J. C., Rabins, P. V., \& Winblad, B. (2001). Current Concepts in Mild Cognitive Impairment. Archives of Neurology, 58, 1985-1992. https://doi.org/10.1001/archneur.58.12.1985

Piper, B. J., Mueller, S. T., Geerken, A. R., Dixon, K. L., Kroliczak, G., Olsen, R. H. J., \& Miller, J. K. (2015). Reliability and Validity of Neurobehavioral Function on the Psychology Experimental Building Language Test Battery in Young Adults. PeerJ, 3, 1460-1462. https://doi.org/10.7717/peerj.1460

Piper, B., Li, V., Eiwaz, M., Kobel, Y., Benice, T., Chu, A., \& Mueller, S. (2012). Executive Function on the Psychology Experiment Building Language Tests. Behaviour Research Methods, 44, 110-123. https://doi.org/10.3758/s13428-011-0096-6

Prakash, R. S., Voss, M. W., Erickson, K. I., Lewis, J. M., Chaddock, L., Malkowski, E., \& Kramer, A. F. (2011). Cardiorespiratory Fitness and Attentional Control in the Aging Brain. Frontiers in Human Neuroscience, 4, 229. https://doi.org/10.3389/fnhum.2010.00229

Predovan, D., Julien, A., Esmail, A., \& Bherer, L. (2019). Effects of Dancing on Cognition in Healthy Older Adults: A Systematic Review. Journal of Cognitive Enhancement, 3, 161-163. https://doi.org/10.1007/s41465-018-0103-2

Rasmusson, X. D., Zonderman, A. B., Kawas, C., \& Resnick, S. M. (1998). Effects of Age and Dementia on the Trail Making Test. The Clinical Neuropsychologist, 12, 169-178. https://doi.org/10.1076/clin.12.2.169.2005

Reitan, R. M., \& Wolfson, D. (1985). The Halstead-Reitan Neuropsychological Test Battery: Theory and Interpretation. Tucson, AZ: Neuropsychology Press.

Rennie, K. L., \& Wareham, N. J. (1998). The Validation of Physical Activity instruments for Measuring Energy Expenditure: Problems and Pitfalls. Public Health Nutrition, 1, 265-271. https://www.ncbi.nlm.nih.gov https://doi.org/10.1079/PHN19980043

Roe, C. M., Xiong, C., Miller, J. P., \& Morris, J. C. (2007). Education and Alzheimer Disease without Dementia: Support for the Cognitive Reserve Hypothesis. Neurology, 68, 223-228. https://doi.org/10.1212/01.wnl.0000251303.50459.8a

Roudaia, E., \& Faubert, J. (2017). Different Effects of Aging and Gender on the Temporal Resolution in Attentional Tracking. Journal of Vision, 17, 1. 


\section{https://doi.org/10.1167/17.11.1}

Roudaia, E., Bennett, P. J., Sekuler, A. B., \& Pilz, K. S. (2010). Spatiotemporal Properties of Apparent Motion Perception and Aging. Journal of Vision, 10, 5-10. https://doi.org/10.1167/10.14.5

Ruiz, J. R., Gil-Bea, F., Bustamante-Ara, N., Rodríguez-Romo, G., Fiuza-Luces, C., Serra-Rexach, J. A., \& Lucia, A. (2015). Resistance Training Does Not Have an Effect on Cognition or Related Serum Biomarkers in Nonagenarians: A Randomized Controlled Trial. International Journal of Sports Medicine, 36, 54-60. https://doi.org/10.1055/s-0034-1375693

Salthouse, T. A. (1996). The Processing-Speed Theory of Adult Age Differences in Cognition. Psychological Review, 103, 403. https://doi.org/10.1037/0033-295X.103.3.403

Salthouse, T. A. (2009). Trajectories of Normal Cognitive Aging. Psychology and Aging, 34, 17-24. https://doi.org/10.1037/pag0000288

Salthouse, T. A. (2011). Neuroanatomical Substrates of Age-Related Cognitive Decline. Psychological Bulletin, 137, 753-784. https://doi.org/10.1037/a0023262

Sanchez-Cubillo, I., Periáñez, J. A., Adrover-roig, D., Rodríguez-sánchez, J. M., Ríos-lago, M., Tirapu, J., \& Barceló, F. (2009). Construct Validity of The Trail Making Test: Role of Task-Switching, Working Memory, Inhibition/Interference Control, and Visuomotor Abilities. Journal of the International Neuropsychological Society, 15, 438-450. https://doi.org/10.1017/S1355617709090626

Sanders, L.M., Hortobagyi, T., Bastide-van Gemert, S., van der Zee, E., \& van Heuvelen, M. (2019). Dose-Response Relationship between Exercise and Cognitive Function in Older Adults with and without Cognitive Impairment: A Systematic Review and Meta-Analysis. PLoS ONE, 14, 103-106. https://doi.org/10.1371/journal.pone.0210036

Schroeder, D. H., \& Salthouse, T. A. (2004). Age-Related Effects on Cognition between 20 and 50 Years of Age. Personality and Individual Differences, 36, 393-404. https://doi.org/10.1016/S0191-8869(03)00104-1

Smith, P. J., Blumenthal, J. A., Hoffman, B. M., Cooper, H., Strauman, T. A., Welsh-Bohmer, K., \& Sherwood, A. (2010). Aerobic Exercise and Neurocognitive Performance: A Meta-Analytic Review of Randomized Controlled Trials. Psychosomatic Medicine, 72, 239-252. https://doi.org/10.1097/PSY.0b013e3181d14633

Snowden, M., Steinman, L., Mochan, K., Grodstein, F., Prohaska, T. R., Thurman, D. J., \& anderson, L. A. (2011). Effect of Exercise on Cognitive Performance in Community-Dwelling Older Adults: Review of Intervention Trials and Recommendations for Public Health Practice and Research. Journal of the American Geriatrics Society, 59, 704-716. https://doi.org/10.1111/j.1532-5415.2011.03323.x

Spencer, R. J., Wendell, C. R., Giggey, P. P., Katzel, L. I., Lefkowitz, D. M., Siegel, E. L., \& Waldstein, S. R. (2013). Psychometric Limitations of the Mini-Mental State Examination among Nondemented Older Adults: An Evaluation of Neurocognitive and Magnetic Resonance Imaging Correlates. Experimental Aging Research, 39, 382-397. https://doi.org/10.1080/0361073X.2013.808109

St. John, P. D., Montgomery, P. R., Kristjansson, B., \& McDowell, I. (2002). Cognitive Scores, Even within the Normal Range, Predict Death and Institutionalization. Age and Aging, 31, 373-378. https://doi.org/10.1093/ageing/31.5.373

Stern, Y. (2009). Cognitive Reserve. New York: Taylor \& Francis. https://doi.org/10.1093/acprof:oso/9780195328875.003.0006

Stern, Y., Arenaza-Urquijo, E. M., Bartrés-Faz, D., Belleville, S., Cantilon, M., Chetelat, G., \& Van Loenhoud, A. C. (2018). Whitepaper: Defining and Investigating Cognitive Reserve, Brain Reserve, and Brain Maintenance. Alzheimer's \& Dementia: The Journal 
of the Alzheimer's Association, 18, 1552-5260.

https://doi.org/10.1016/j.jalz.2018.07.219

Stewart, A. L., Mills, K. M., King, A. C., Haskell, W. L., Gillis, D., \& Ritter, P. L. (2001). CHAMPS Physical Activity Questionnaire for Older Adults: Outcomes for Interventions. Medicine and Science in Sports and Exercise, 33, 1126-1141. https://doi.org/10.1097/00005768-200107000-00010

Strauss, E., Sherman, E. M. S., \& Spreen, O. (2006). A Compendium of Neuropsychological Tests: Administration, Norms, and Commentary (3rd ed.). New York: Oxford University Press.

Tabachnick, B. G., \& Fidell, L. S. (2013). Using Multivariate Statistics (6th ed.). Harlow, UK: Pearson Education.

Tabara, Y., Yuasa, T., Oshiumi, A., Kobayashi, T., Miyawaki, Y., Miki, T., \& Kohara, K. (2007). Effect of Acute and Long-Term Aerobic Exercise on Arterial Stiffness in the Elderly. Hypertension Research, 30, 895-902. https://doi.org/10.1291/hypres.30.895

Tombaugh, T. N. (2004). Trail Making Test A and B: Normative Data Stratified By Age and Education. Archives of Clinical Neuropsychology, 19, 203-214.

https://doi.org/10.1016/S0887-6177(03)00039-8

Uttl, B. (2008). Transparent Meta-Analysis of Prospective Memory and Aging. PLoS ONE, 3, 156-158. https://doi.org/10.1371/journal.pone.0001568

Vaportzis, E., Niechcial, M. A., \& Gow, A. J. (2019). A Systematic Literature Review and Meta-Analysis of Real-World Interventions for Cognitive Aging in Healthy Older Adults. Aging Research Reviews, 50, 110-130. https://doi.org/10.1016/j.arr.2019.01.006

Vaughan, S., Wallis, M., Polit, D., Steele, M., Shum, D., \& Morris, N. (2014). The Effects of Multimodal Exercise on Cognitive and Physical Functioning and Brain-Derived Neurotrophic Factor in Older Women: A Randomised Controlled Trial. Age and Aging, 43, 623-629. https://doi.org/10.1093/ageing/afu010

Vemuri, P., Lesnick, T. G., Przybelski, S. A., Knopman, D. S., Roberts, R. O., Lowe, V. J., \& Jack, C. R. (2012). Effect of Lifestyle Activities on Alzheimer Disease Biomarkers and Cognition. Annals of Neurology, 72, 730-738. https://doi.org/10.1002/ana.23665

Voss, M. W., Nagamatsu, L. S., Liu-Ambrose, T., \& Kramer, A. F. (2011). Exercise, Brain, and Cognition across the Life Span. Journal of Applied Physiology, 111, 1505-1513. https://doi.org/10.1152/japplphysiol.00210.2011

Walsh, N. P. (2018). Recommendations to Maintain Immune Health in Athletes. European Journal of Sport Science, 18, 820-831. https://doi.org/10.1080/17461391.2018.1449895

Wearden, J. H., Wearden, A. J., \& Rabbitt, P. M. A. (1997). Age and IQ Effects on Stimulus and Response Timing. Journal of Experimental Psychology: Human Perception and Performance, 23, 962-979. https://doi.org/10.1037/0096-1523.23.4.962

Wilke, J., Giesche, F., Klier, K., Vogt, L., Herrmann, E., \& Banzer, W. (2019). Acute Effects of Resistance Exercise on Cognitive Function in Healthy Adults: A Systematic Review with Multilevel Meta-Analysis. Sports Medicine, 49, 905-916.

https://doi.org/10.1007/s40279-019-01085-X

Wong, C. N., Chaddock-Heyman, L., Voss, M. W., Burzynska, A. Z., Basak, C., Erickson, K. I., \& Kramer, A. F. (2015). Brain Activation During Dual-Task Processing Is Associated with Cardiorespiratory Fitness and Performance in Older Adults. Frontiers in Aging Neuroscience, 7, 154-159. https://doi.org/10.3389/fnagi.2015.00154

World Health Organisation (WHO) (2012). Dementia: A Public Health Priority. Albany: World Health Organization. https://ebookcentral.proquest.com 
Yaffe, K., Fiocco, A. J., Lindquist, K., Vittinghoff, E., Simonsick, E. M., Newman, A. B., \& Harris, T. B. (2009). Predictors of Maintaining Cognitive Function in Older Adults: The Health ABC Study. Neurology, 72, 2029-2035.

https://doi.org/10.1212/WNL.0b013e3181a92c36

Yeung, C., St. John, P., Menec, V., \& Tyas, S. (2014). Is Bilingualism Associated with a Lower Risk of Dementia in Community-Living Older Adults? Cross-Sectional and Prospective Analyses. Alzheimer Disease \& Associated Disorders, 28, 326-332.

https://doi.org/10.1097/WAD.0000000000000019

Younan, B. (2018). Cognitive Functioning Differences between Physically Active and Sedentary Older Adults. Journal of Alzheimer's Disease Reports, 2, 93-101. https://doi.org/10.3233/ADR-180053

Young, J., Angevaren, M., Rusted, J., \& Tabet, N. (2015). Aerobic Exercise to Improve Cognitive Function in Older People without Known Cognitive Impairment. Cochrane Database of Systematic Reviews, 22, 538-546.

https://doi.org/10.1002/14651858.CD005381.pub4

Yuan, P., \& Raz, N. (2014). Prefrontal Cortex and Executive Functions in Healthy Adults: A Meta-Analysis of Structural Neuroimaging Studies. Neuroscience and Biobehavioral Reviews, 42, 180-192. https://doi.org/10.1016/j.neubiorev.2014.02.005

Zaninotto, P., Batty, G. D., Allerhand, M., \& Deary, I. J. (2018). Cognitive Function Trajectories and Their Determinants in Older People: 8 Years of Follow-up in the English Longitudinal Study of Aging. Journal of Epidemiology and Community Health, 72, 685-694. https://doi.org/10.1136/jech-2017-210116

Zhang, Z., Li, L. W., Xu, H., \& Liu, J. (2019). Does Widowhood Affect Cognitive Function among Chinese Older Adults? SSM-Population Health, 7, 100-104.

https://doi.org/10.1016/j.ssmph.2018.100329 